\title{
Dynamics of Human Mitochondrial Complex I Assembly: Implications for Neurodegenerative Diseases
}

\author{
Gabriele Giachin, Romain Bouverot, Samira Acajjaoui, Serena Pantalone and \\ Montserrat Soler-López *
}

Structural Biology Group, European Synchrotron Radiation Facility, Grenoble, France

OPEN ACCESS

Edited by:

Luca Mollica,

Italian Institute of Technology, Italy

Reviewed by:

Revati Wani,

Pfizer, USA

Trevor P. Creamer,

University of Kentucky, USA

*Correspondence:

Montserrat Soler-López montserrat.soler-lopez@esrf.fr

Specialty section:

This article was submitted to

Molecular Recognition,

a section of the journal

Frontiers in Molecular Biosciences

Received: 07 June 2016 Accepted: 02 August 2016 Published: 22 August 2016

Citation:

Giachin G, Bouverot R, Acajjaoui S,

Pantalone $S$ and Soler-López M

(2016) Dynamics of Human

Mitochondrial Complex I Assembly: Implications for Neurodegenerative

Diseases. Front. Mol. Biosci. 3:43.

doi: 10.3389/fmolb.2016.00043
Neurons are extremely energy demanding cells and highly dependent on the mitochondrial oxidative phosphorylation (OXPHOS) system. Mitochondria generate the energetic potential via the respiratory complexes I to IV, which constitute the electron transport chain (ETC), together with complex $V$. These redox reactions release energy in the form of ATP and also generate reactive oxygen species (ROS) that are involved in cell signaling but can eventually lead to oxidative stress. Complex I (Cl or NADH:ubiquinone oxidoreductase) is the largest ETC enzyme, containing 44 subunits and the main contributor to ROS production. In recent years, the structure of the $\mathrm{Cl}$ has become available and has provided new insights into $\mathrm{Cl}$ assembly. A number of chaperones have been identified in the assembly and stability of the mature holo- $\mathrm{Cl}$, although they are not part of its final structure. Interestingly, $\mathrm{Cl}$ dysfunction is the most common OXPHOS disorder in humans and defects in the $\mathrm{Cl}$ assembly process are often observed. However, the dynamics of the events leading to $\mathrm{Cl}$ biogenesis remain elusive, which precludes our understanding of how ETC malfunctioning affects neuronal integrity. Here, we review the current knowledge of the structural features of $\mathrm{Cl}$ and its assembly factors and the potential role of $\mathrm{Cl}$ misassembly in human disorders such as Complex I Deficiencies or Alzheimer's and Parkinson's diseases.

Keywords: complex I, MCIA, assembly factors, mitochondrial dysfunction, neurodegeneration, Alzheimer's disease, Parkinson's disease

\section{INTRODUCTION}

The major mechanisms mediating neuronal activity are all initially powered by the oxidative phosphorylation system (OXPHOS) in mitochondria, the so-called "powerhouse" of the cell (Hall et al., 2012). They generate energetic potential through the electron transport chain (ETC) which includes complex I (CI or NADH:ubiquinone oxidoreductase), complex II (CII or succinate:ubiquinone oxidoreductase), complex III (CIII or ubiquinol:cytochrome-c oxidoreductase), and complex IV (CIV or cytochrome-c oxidase). Together with complex V

Abbreviations: OXPHOS, oxidative phosphorylation system; CI, complex I; ETC, electron transfer chain; ROS, reactive oxygen species; mtDNA, mitochondrial DNA; FAD, flavine adenine nucleotide; MTS, mitochondrial targeting sequence; MCIA, mitochondrial CI assembly; ND, neurodegenerative diseases; AD, Alzheimer's disease; PD, Parkinson's disease; CID, complex I deficiencies; LS, Leigh syndrome; MELAS, mitochondrial encephalomyopathy, lactic acidosis and strokelike episodes syndrome; NARP, neuropathy, ataxia, and retinitis pigmentosa syndrome; tg mice, transgenic mice; NFT, neurofibrillary tangles; $\mathrm{A} \beta$, amyloid- $\beta$ peptide; APP, amyloid precursor protein. 
(CV or $\mathrm{F}_{\mathrm{O}} \mathrm{F}_{1}$-ATP-synthase) they form what is usually called the OXPHOS system. Biogenesis of a functional OXPHOS system requires a large set $(>92)$ of mitochondrial- and nuclear-encoded proteins (Koopman et al., 2013). Despite the critical importance of the CI in energy production, many aspects of its structure, assembly and activity are still poorly understood. Here, we provide an overview of the current knowledge of CI structure and the factors involved in its assembly, with an emphasis on the Mitochondrial Complex I Assembly (MCIA) complex. We then examine the supporting evidence that correlates CI dysfunction and misassembly with neurodegeneration, in particular Complex I Deficiencies, Alzheimer's and Parkinson's diseases. Overall, this review attempts to explore recent advances into the molecular mechanisms of CI assembly based on structural and clinical studies in order to provide a better understanding of its underlying mechanisms in neurodegenerative disorders.

\section{MITOCHONDRIAL ENERGY PRODUCTION IN NEURONS: THE CRITICAL ROLE OF THE OXIDATIVE PHOSPHORYLATION SYSTEM}

As a first step in oxidative phosphorylation, fuel molecules (such as monosaccharides and fatty acids) are transferred to nicotinamide (NAD) and flavine adenine (FAD) nucleotides through glycolysis, Krebs cycle and $\beta$-oxidation and are then oxidized through the ETC. CI, CIII, and CIV generate proton force in the intermembrane space and their actions are facilitated by CII and electron transfer cofactors (i.e., ubiquinone and cytochrome-c). Proton translocation back to the mitochondrial matrix drives $\mathrm{CV}$, which is coupled to ATP synthesis. Most of the ATP produced by $\mathrm{CV}$ is exchanged against cytosolic ADP through a specific adenine nucleotide carrier to supply the rest of the cell with energy and to maintain the ADP phosphorylation capacity of mitochondria (Lasserre et al., 2015).

Many inner membrane transporters are also driven by the electrochemical proton gradient, which is required for the maintenance of mitochondrial integrity and essential functions like apoptosis, innate immunity, redox control, calcium homeostasis, and several biosynthetic processes (Koopman et al., 2013).

The redox reactions involved in energy production generate reactive oxygen species (ROS), which have important roles in cell signaling and homeostasis. However, high levels of ROS can also lead to oxidative stress. ROS levels are particularly critical in the central nervous system (CNS) since neurons are extremely energy demanding but have limited glycolysis, making them highly dependent on an efficient OXPHOS. The ability of the brain to withstand oxidative stress is limited because of (a) high content of easily oxidizable substrates; (b) relatively low levels of antioxidants; (c) the endogenous generation of ROS via several specific reactions; (d) the elevated content of iron in specific areas of the human brain, and (e) CNS contains non-replicating neuronal cells which, once damaged, may be permanently dysfunctional or committed to apoptosis (Calabrese and Halpain, 2005; Cao and Fang, 2015; Wakatsuki et al., 2015). Thus, it is not surprising that mitochondria of synaptic origin can be highly affected in response to physiological or environmental alterations, with severe consequences for neuronal function and survival. Metabolically, there is evidence that both neurons and astrocytes rely on OXPHOS for ATP generation, whereas astrocytes also possess energy stores in the form of glycogen (Hertz et al., 2007; Belanger et al., 2011). Moreover, the ability of mitochondria to move within the cells is also critical in highly polarized cells like neurons. Data from rat brain mitochondria of non-synaptic origin have shown that ETC complex activities need to be reduced by at least $60 \%$ before major changes in ATP synthesis and oxygen consumption occur. However, in synaptic mitochondria, titration of various ETC complexes with specific inhibitors show that decreased CI, III, and IV activities of 25, 80 , and $70 \%$, respectively, result in major changes in rates of oxygen consumption and ATP synthesis (Telford et al., 2009). This suggests that in mitochondria of synaptic origin, CI activity has a major control of oxidative phosphorylation, such that when a relatively low threshold of $25 \%$ inhibition is exceeded, energy metabolism is compromised, and reduction in ATP synthesis ensues (Telford et al., 2009).

Even though the basic functional principles of most components of the ETC have been elucidated, the details are still being hotly debated. We now know that each complex in the chain functions with a unique mechanism and that there are no direct analogs with other enzymes (Sazanov, 2015).

\section{MITOCHONDRIAL RESPIRATORY COMPLEX I: STRUCTURE AND FUNCTION}

$\mathrm{CI}$ is the largest and first enzyme of the ETC. It is essential for cellular energy production, providing about $40 \%$ of the proton motive force required for ATP synthesis. It oxidizes NADH to $\mathrm{NAD}^{+}$and donates the released electrons to the electron carrier coenzyme $\mathrm{Q}_{10}\left(\mathrm{CoQ}_{10}\right.$, also known as ubiquinone), linking this process to the translocation of four protons from the mitochondrial matrix to the intermembrane space (Figure 1; Sazanov, 2014). These electron transfers generate superoxide $\left(\mathrm{O}_{2}^{-}\right)$, which is the proximal mitochondrial ROS (St-Pierre et al., 2002; Kussmaul and Hirst, 2006; Murphy, 2009). Superoxide is normally converted to $\mathrm{H}_{2} \mathrm{O}_{2}$ by manganese superoxide dismutase (MnSOD); the latter can easily diffuse across the membranes and be quickly reduced to water by mitochondrial and cytoplasmic peroxiredoxins, catalases, and glutathione peroxidases (Cox et al., 2010; Li et al., 2013).

Mammalian CI is composed of 44 different subunits, all of which are integral components of the enzyme (approximately $1 \mathrm{MDa}$ ). Seven of these subunits (ND1, ND2, ND3, ND4, ND4L, ND5, and ND6) are encoded by the mitochondrial DNA (mtDNA) and the rest by the nuclear DNA (Vinothkumar et al., 2014). The prokaryotic counterpart of CI contains only the 14 highly conserved core subunits (a total mass of about $550 \mathrm{kDa}$ ), which harbor the bioenergetic functions. The extra counterparts seen in mammalian CI are thus called accessory or supernumerary subunits (Letts and Sazanov, 2015). 




While the atomic-resolution structures and basic mechanisms of most respiratory complexes have been previously established, there are still large gaps in our understanding of the coupled electron transport and proton pumping in the OXPHOS complexes, being the CI the least understood (Letts and Sazanov, 2015). Crystal structures have been reported for prokaryotic CIs (also called NADH dehydrogenase-1) such as from Escherichia coli (Efremov and Sazanov, 2010, 2011), T. thermophilus (Baradaran et al., 2013), P. denitrificans (Sedlacek et al., 2014), and A. aeolicus (Yeh et al., 2000), reviewed in Berrisford and Sazanov (2009). Structural models are also available for eukaryotic CI, such as from the obligate aerobic yeast $Y$. lipolytica (Zickermann et al., 2015) and the fungus Neurospora crassa (Janssen et al., 2006). Furthermore, the recent cryo-EM structure of bovine heart $\mathrm{CI}$ has enabled the molecular modeling of the 14 core subunits plus 14 of the supernumerary subunits of the mammalian enzyme (Vinothkumar et al., 2014). Nevertheless, higher resolution data are still required for a full assignment of the rest of the supernumerary subunits to build a complete mammalian CI structural model (Letts and Sazanov, 2015).

Eukaryotic CI seems to be organized into four functional modules (Figure 1). It forms an L-shaped arm, composed of 
hydrophilic (matrix-protruding and peripheral) and lipophilic (inner membrane-embedded) segments (Clason et al., 2010). The two constituents have independent functions. The peripheral arm extends into the matrix and is responsible for the electron transfer reaction while the membrane arm catalyzes proton transport (Sazanov, 2015). The distal half of the matrix arm forms the $\mathrm{N}$ module that is made up of the central 75,51 , and $24-\mathrm{kDa}$ subunits and contains the dehydrogenase site, formed by a flavinmononucleotide (FMN) moiety and responsible for the oxidation of NADH to $\mathrm{NAD}^{+}$. The proximal half of the peripheral arm is the $\mathrm{Q}$ module. This reduces ubiquinone and is composed of the central $49-\mathrm{kDa}, 30-\mathrm{kDa}$, PSST, and TYKY subunits, docking onto the membrane arm. A chain of eight iron-sulfur clusters runs over a distance of about $100 \AA$ through the matrix arm allowing fast electron tunneling (Zickermann et al., 2015) in a very similar manner to that seen in prokaryotic CI, except that, owing to rotation of the $51-$ and $24-\mathrm{kDa}$ subunits, the mammalian counterpart chains are more distal to the membrane and more divergent (Vinothkumar et al., 2014). The membrane arm contains 82 transmembrane helices (TMHs), 64 of them contributed by central subunits. The mammalian membrane domain is more strongly curved out of the membrane plane than the prokaryotic analog, mainly due to a transmembrane helix in subunit ND6 (Vinothkumar et al., 2014). The proximal pump module $\left(\mathrm{P}_{\mathrm{P}}\right)$ comprises the central subunits ND1, ND2, ND3, ND4L, and ND6, whereas the distal pump module $\left(\mathrm{P}_{\mathrm{D}}\right)$ contains the central subunits ND4 and ND5. The interior of the membrane arm is rich in polar and protonable residues (i.e., residues that may take up or release protons) constituting a remarkable hydrophilic central axis across all subunits (Zickermann et al., 2015).

Taken together, the overall architecture of the CI supports the idea that proton translocation is driven by long-range conformational changes. However, the energy-converting mechanism of CI remains largely unknown (Hirst and Roessler, 2015; Letts and Sazanov, 2015). Furthermore, many important structural details remain to be elucidated, including, for instance, the role of several single transmembrane ancillary subunits, which are proposed to form a scaffold structure holding the giant complex during its oscillatory movements; or when and how the different prosthetic groups are incorporated into the complex (Ghezzi and Zeviani, 2012). Along this line, CI has been long known to be inhibited by $\mathrm{Zn}^{2+}$, but the site of inhibitory $\mathrm{Zn}^{2+}$ binding remains to be identified (Hirst and Roessler, 2015).

\section{COMPLEX I CONSTRUCTION: THE CRITICAL ROLE OF ASSEMBLY FACTORS}

Specific pathways are required for the assembly of each ETC complex, including the transfer of nuclear and mtDNA-encoded ETC subunits into the inner membrane of mitochondria; the synthesis and incorporation of several prosthetic groups that form the catalytic redox cores of CI, CII, CIII, and CIV; and the ultimate formation of functionally active holo-complexes, which can also organize themselves in respiratory supercomplexes (Ghezzi and Zeviani, 2012). Additional systems verify the quality control of protein and non-protein components of the ETC complexes, contributing to the maintenance of their structural integrity, functional activity, and turnover. Thus, a highly regulated, extremely complex process is at work in mitochondria to control the formation, stability, interactions, function, and plasticity of the ETC (Ghezzi and Zeviani, 2012).

CI assembly is a complicated multistep process. Previous studies on mammalian CI biogenesis have used patient cells containing assembly defects to generate models of CI assembly (Lazarou et al., 2007). The presence of CI subunits in mobile (matrix-soluble) and/or immobile (membrane-bound) subassemblies in vivo indicates that a modular CI assembly pathway is operational in different mitochondrial compartments in the living cell (Dieteren et al., 2008). In addition, in human mitochondria $\mathrm{CI}$ is found exclusively as a component of respiratory supercomplexes, since it requires CIII for stability (Schagger et al., 2004; Moreno-Lastres et al., 2012). Although it is not known exactly how each subunit is assembled to form the mature CI in humans, a model for its assembly has been developed in recent years (Vogel et al., 2007b; Mckenzie and Ryan, 2010). Based on this, a stepwise assembly process of CI would involve pre-assembled modules of the peripheral matrix and membrane arms (Figure 1; Letts and Sazanov, 2015). Even if current data on CI assembly accounts for the addition of only 16 of the 30 mammalian mitochondria supernumerary subunits, they still provide strong clues concerning to which of the core subunits these supernumerary subunits are binding (Letts and Sazanov, 2015). Consistent with the highly hydrophobic nature of the proteins located in the $\mathrm{P}$ module, the membrane arm forms an assembly intermediate, including ND2, ND4, ND4L, ND5, and ND6 mitochondrial subunits before the progression into the mature holo-enzyme (Leman et al., 2015). Nevertheless, previous studies have demonstrated that subassemblies of nuclear DNA-encoded CI subunits could be formed in the absence of mtDNA-encoded subunits, suggesting that the presence of the mitochondrial-encoded subunits is not required for the formation of the peripheral arm subcomplex (Potluri et al., 2004). The Q module seems to assemble separately from the $\mathrm{N}$ module and associate with the membrane arm in a late stage intermediate of roughly $830 \mathrm{kDa}$. In a last step, the subunits of the tip of CI, i.e., subunits of the $\mathrm{N}$ module (core catalytic NDUFV1, NDUFV2, and NDUFS1 subunits and accessory NDUFV3, NDUFS4, 6 and NDUFA12 subunits) seem to be added to form a functional holo-enzyme (reviewed in Mckenzie and Ryan, 2010).

The integration of these subunits and insertion of cofactors into the nascent $\mathrm{CI}$ is aided by assembly factors, which tend to be specific for each complex but bind transiently without forming part of the final enzyme (Fernandez-Vizarra et al., 2009; Torraco et al., 2015; Sanchez-Caballero et al., 2016; Wirth et al., 2016). At least 13 assembly factors have now been identified and characterized to be involved in CI assembly (Table 1; Mimaki et al., 2012). They are encoded in the nucleus and are then delivered to the mitochondria. To ensure proper delivery, the majority contains a specific $\mathrm{N}$-terminal signal presequence, also called mitochondrial targeting sequence (MTS) that is removed after import by the mitochondrial processing peptidase. Nevertheless, some proteins do not contain a cleavable 
TABLE 1 | $\mathrm{Cl}$ assembly factors and interacting $\mathrm{Cl}$ subunits.

\begin{tabular}{|c|c|c|c|}
\hline Interactors & Description & $\mathrm{Cl}$ interacting subunits & References \\
\hline ACAD9 & $\begin{array}{l}\text { Acyl-CoA dehydrogenase family } \\
\text { member } 9 \text {, mitochondrial }\end{array}$ & $\begin{array}{l}\text { Core: NDUFS2, NDUFS3, NDUFS7, ND6 } \\
\text { Accessory: NDUFA13, NDUFS5 }\end{array}$ & Nouws et al., 2010 \\
\hline ECSIT & $\begin{array}{l}\text { Evolutionarily conserved signaling } \\
\text { intermediate in Toll pathway, } \\
\text { mitochondrial }\end{array}$ & $\begin{array}{l}\text { Core: NDUFS1, NDUFS2, NDUFS3, NDUFS8, ND1, ND4 } \\
\text { Accessory: NDUFA3, NDUFA8, NDUFA13, NDUFB1, } \\
\text { NDUFB5, NDUFB8, NDUFB11, NDUFS5, NDUFC2 }\end{array}$ & Vogel et al., 2007a \\
\hline NDUFAF1 & $\begin{array}{l}\text { Complex I intermediate-associated } \\
\text { protein } 30 \text {, mitochondrial }\end{array}$ & $\begin{array}{l}\text { Core: NDUFS1, NDUFS3, NDUFS7, ND1 } \\
\text { Accessory: NDUFA8, NDUFA9, NDUFA12, NDUFA13, } \\
\text { NDUFB6, NDUFB11, NDUFS5 }\end{array}$ & Vogel et al., 2005 \\
\hline NDUFAF4 & $\begin{array}{l}\text { NADH dehydrogenase [ubiquinone] } 1 \\
\text { alpha subcomplex assembly factor } 4\end{array}$ & $\begin{array}{l}\text { Core: NDUFS3, NDUFS7 } \\
\text { Accessory: NDUFA13, NDUFS5 }\end{array}$ & Saada et al., 2008 \\
\hline NDUFAF5 & $\begin{array}{l}\text { NADH dehydrogenase [ubiquinone] } 1 \\
\text { alpha subcomplex assembly factor } 5\end{array}$ & $\begin{array}{l}\text { Core: NDUFS3, NDUFS7 } \\
\text { Accessory: NDUFA10 }\end{array}$ & Sugiana et al., 2008 \\
\hline NDUFAF6 & $\begin{array}{l}\text { NADH dehydrogenase [ubiquinone] } 1 \\
\text { alpha subcomplex assembly factor } 6\end{array}$ & n.d. & McKenzie et al., 2011 \\
\hline TMEM126B & $\begin{array}{l}\text { Complex I assembly factor } \\
\text { TMEM126B (Transmembrane protein } \\
\text { 126B), mitochondrial }\end{array}$ & Accessory: NDUFA13 & Heide et al., 2012 \\
\hline
\end{tabular}

Interactions curated by Intact (Orchard, 2014) and Biogrid (Chatraryamontri et al., 2015). n.d., no data available.

MTS. These include three CI assembly factors: TMEM126B, FOXRED1, and TIMMDC1 (Sanchez-Caballero et al., 2016). How assembly factors function is not known, but they may act as chaperones that stabilize the subcomplexes and help them to associate to other subcomplexes in order to build the complete enzyme (Vogel et al., 2007b; Andrews et al., 2013). The fact that crystal structures of the assembly factors are not available precludes our understanding of the mechanistic basis of these proteins at the molecular level (Guarani et al., 2014). These assembly chaperones may have additional functions besides their requirement for $\mathrm{CI}$ assembly, in line with the evidence that mitochondria are more than energy producers and are involved with various (sub)cellular processes that ultimately regulate mitochondrial metabolic activity (Vogel et al., 2007b).

\section{The Mitochondrial Complex I Assembly (MCIA) Complex}

Most currently identified CI assembly factors are involved in early assembly and more specifically in the incorporation of the hydrophobic membrane subunits. The CI assembly factors NDUFAF1, ACAD9, ECSIT, TMEM126B, and TIMMDC1 form 
the MCIA complex (Heide et al., 2012), which was first identified in rat heart mitochondria and then in human osteosarcoma 143B cells by complexome profiling (Heide et al., 2012). The MCIA complex seems to associate with the $370-\mathrm{kDa}$ subcomplex intermediate, consisting of subunits of the membrane P-proximal submodule (Figure 1; Lazarou et al., 2007; Andrews et al., 2013).

\section{NDUFAF1}

NDUFAF1 (NADH dehydrogenase [ubiquinone] 1 alpha subcomplex assembly factor 1) is a mitochondrial protein comprising 327 amino acids including a predicted 24 residue N-terminal MTS (Figure 2A). NDUFAF1 interacts with nuclearand mitochondrial-encoded CI subunits (Supplementary Table 1; Dunning et al., 2007). siRNA-mediated knockdown of NDUFAF1 results in decreased CI activity and levels, while overexpression of NDUFAF1 leads to an increase in the CI expression (Vogel et al., 2005). Based on these results, NDUFAF1 has been proposed to be a chaperone transiently interacting with CI intermediates (Kuffner et al., 1998; Vogel et al., 2007b) but the mechanistic details are still elusive.

NDUFAF1 has been identified as the human homolog of $N$. crassa CI intermediate-associated protein 30 (CIA30) and is moderately conserved among species, sharing $28 \%$ identity and exhibiting the highest homology in the C-terminal region of the protein (Vogel et al., 2005; Figure 2, Supplementary Figure 1). Interestingly, using structural profile-based homology searches, the C-terminal region of NDUFAF1 shows a high similarity to Galactose-binding domain-like proteins, in particular to the noncatalytic carbohydrate binding module family 11 (CBM11; Viegas et al., 2008; Figure 2, Supplementary Figure 1). These modules fold as a $\beta$-sandwich structure with a high degree of similarity between different family members despite an often low level of sequence similarity. They usually exist within large enzymes, being involved in recognizing the appropriate glucans for the catalytic domain and in localizing those domains onto the surface of the polysaccharide substrates (Elurbe and Huynen, 2016).

The N-terminal region of NDUFAF1 appears to contain a putative RNA recognition motif (RRM; Figure 2, Supplementary Figure 1; Marchler-Bauer et al., 2015). The RRM superfamily, also known as RBD (RNA binding domain) or RNP (ribonucleoprotein domain), is a highly abundant domain in eukaryotes and is found in proteins involved in posttranscriptional gene expression processes including mRNA and rRNA processing, RNA export, and RNA stability. This domain is generally 90 amino acids in length with a tertiary structure consisting of a four-stranded $\beta$-sheet packed against two $\alpha$-helices. RRM usually interacts with single-stranded RNA, but is also known to interact with single-stranded DNA and proteins. RRM binds to a variable number of nucleotides, ranging from two to eight (Dreyfuss et al., 1988). In NDUFAF1 this domain is predicted to be highly disordered and to be involved in protein-protein interactions (Figure 2B). NDUFAF1



B

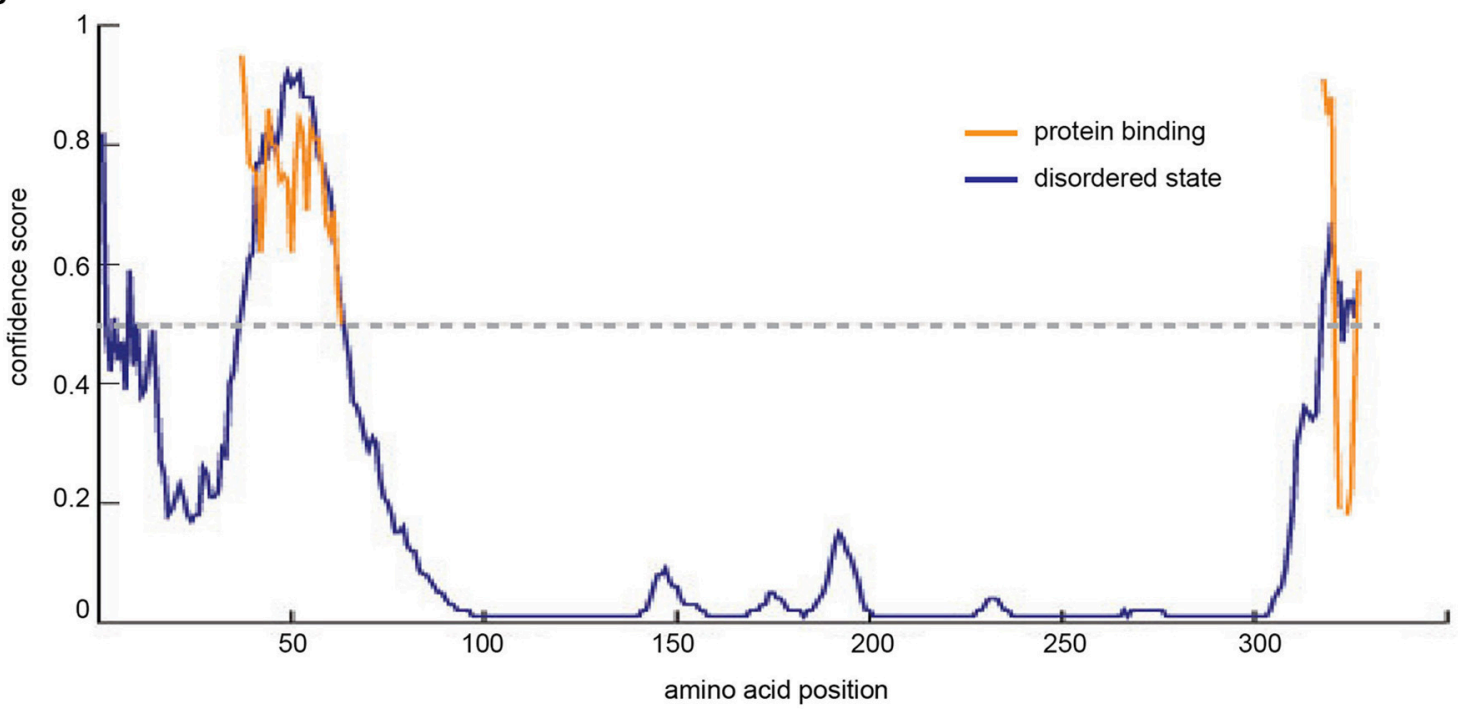

FIGURE 2 | NDUFAF1 protein domain organization. (A) Human NDUFAF1 predicted domain organization. MTS: mitochondrial signal peptide (residues 1-24). RRM: predicted RNA recognition motif (residues 14-101) based on a BLAST conservation domain alignment [(Marchler-Bauer et al., 2015); superfamily member Cl17169, Pssm-ID:277499, E-value = 5.72e-04]. The C-terminal half of the protein belongs to the CIA30 family domain [(residues 125-298); superfamily member Cl21728, PSSm-ID:272148, E-value = 6.40e-55], which is predicted to include a carbohydrate-binding module (CMB11) based on InterPro server (ID:IPR005087; Mitchell et al., 2015). (B) Prediction of disorder tendency of the full-length NDUFAF1 with PSIPRED server (Buchan et al., 2013). High-confidence protein binding sites are shown in orange lines. 
also contains putative phosphorylation sites such as Ser18 located in the leader sequence and Ser199 located in the central region (Supplementary Figure 1, residues highlighted in pink; Janssen et al., 2002). Interestingly, a cAMP-dependent protein kinase phosphorylation site, located on the $18 \mathrm{kDa}$ subunit of CI, has been shown to be involved in the activation of the complex (Janssen et al., 2002).

\section{ECSIT}

ECSIT (Evolutionarily conserved signaling intermediate in Toll pathway) is an adapter protein of 431 amino acids (Kopp et al., 1999). There are 4 predicted isoforms but only isoforms 1 and 2 have been detected at protein level (Kopp et al., 1999; Xiao et al., 2003). Although ECSIT was initially identified as a cytoplasmic and nuclear signaling protein (Kopp et al., 1999; Xiao et al., 2003) an N-terminal MTS (first 48 amino acids) can direct ECSIT to mitochondria (Vogel et al., 2007a; Figure 3A).

The N-terminal region of ECSIT (spanning from residues 90 to 266 approximately) seems to be highly ordered (Figure 3B) and to contain pentatricopeptide repeats (PPR; Supplementary Figure 2). PPRs are 35-residue repeat motifs that form two anti-parallel $\alpha$-helices organized into tandem repeats, typically binding single-stranded RNA in a sequence-specific and modular manner. They were first identified in plant organelles but an important role in mammalian mitochondrial gene regulation is now emerging (Rackham and Filipovska, 2012). PPRs are involved in many aspects of RNA metabolism such as maturation, translation and stabilizing organelle transcripts. Interestingly, PPR domain proteins (PTCDs) are predicted to be involved in the assembly of ETC complexes (Lightowlers and ChrzanowskaLightowlers, 2008). Taken together, although no RNA binding for ECSIT nor NDUFAF1 has been reported, the fact that they both may contain an RNA binding domain suggests that the MCIA complex could also be involved in complex biogenesis by regulating the RNA processing of mitochondrial-encoded CI subunits (Rackham and Filipovska, 2012; Lightowlers and Chrzanowska-Lightowlers, 2013; Olahova et al., 2015).

The C-terminal domain of ECSIT shows a higher intrinsic disorder degree (Figure 3B) and only occurs in metazoa, indicating that ECSIT itself is also limited to this taxon, i.e., the filozoa (Elurbe and Huynen, 2016). Fold recognition suggests that this domain may be distantly homologous to the

A

Evolutionarily conserved signalling intermediate in Toll pathway (ECSIT)



B

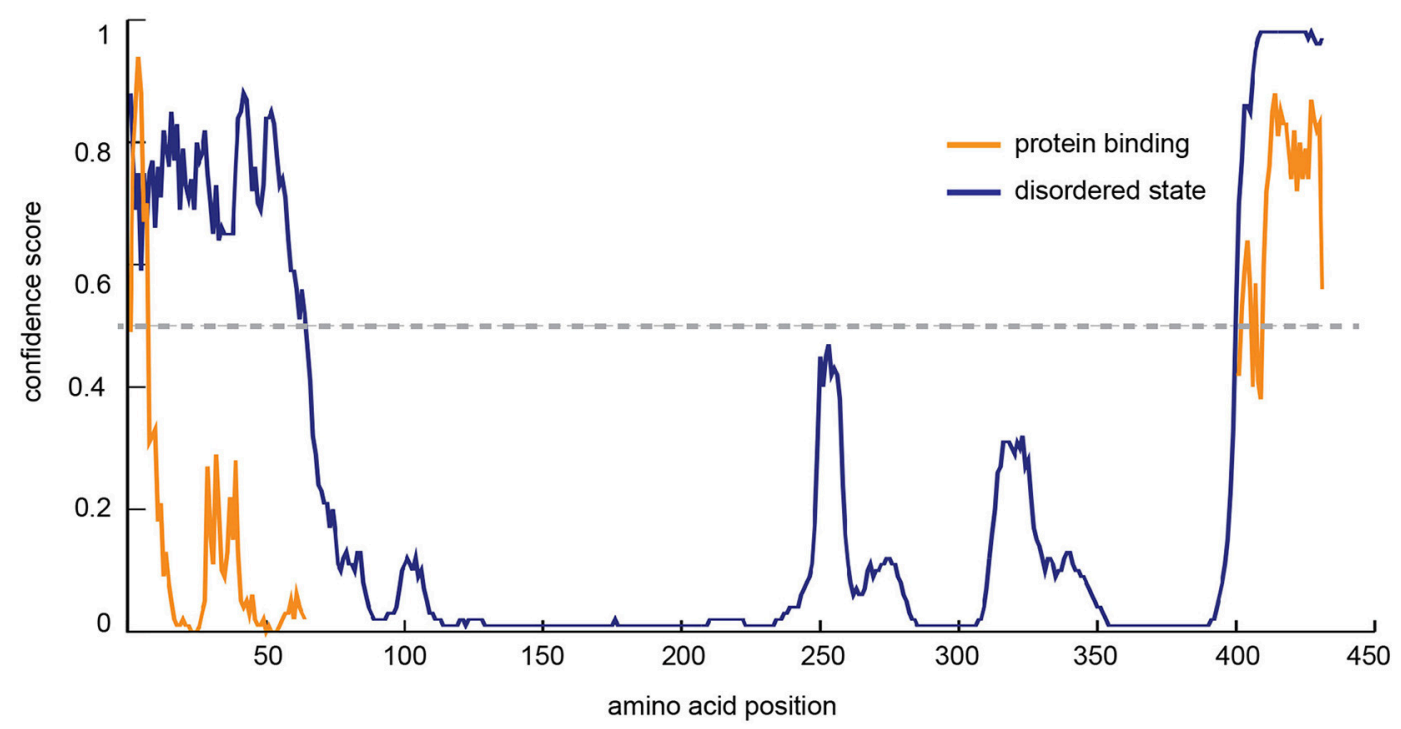

FIGURE 3 | ECSIT protein domain organization. (A) Human ECSIT canonical isoform 1 and isoform 2 predicted domain organization, respectively. MTS: mitochondrial signal peptide (residues 1-48). PPR: pentatricopeptide repeat motif (central residues 90-266) based on a BLAST conservation domain alignment [Pssm-ID:276811, Threshold Bit Score = 35.6508 (Marchler-Bauer et al., 2015)]. The C-terminal part seems to fold like a pleckstrin homology (PH) domain (residues 275-380) based on the structure-based homology model server Phyre2 (Kelley et al., 2015). (B) Prediction of disorder tendency of the full-length ECSIT with PSIPRED server (Buchan et al., 2013). High-confidence protein binding sites are shown in orange lines. 
pleckstrin homology (PH) domain (Kelley et al., 2015). Despite minimal sequence homology, the three-dimensional structure is remarkably conserved among $\mathrm{PH}$ domains, with minimal secondary structure elements consisting of seven $\beta$-strands and one C-terminal $\alpha$-helix (Rebecchi and Scarlata, 1998). The number and variety of host proteins with $\mathrm{PH}$ motifs is large but most of them can be grouped by function into a few classes: Ser/Thr protein kinases, Tyr protein kinases, small G-protein regulators, endocytic GTPases, adaptors, phosphoinositide metabolizing enzymes, and cytoskeletal associated proteins (Rebecchi and Scarlata, 1998). Many of them contain a catalytic domain (e.g., kinase) and other adaptor domains (e.g., SH2 or SH3) and they are often the targets for protein kinases (Rebecchi and Scarlata, 1998). Notably, ECSIT isoform 2 lacks this domain and seems to be involved in the BMP signaling pathway as a SMAD cofactor, required for normal embryonic development (Xiao et al., 2003).

ECSIT interacts with a ubiquitin ligase called TRAF6 (tumor necrosis factor receptor-associated factor 6) and it is involved in phosphorylation and activation of the nuclear factor NF-kB pathway in innate immunity (Kopp et al., 1999). Ubiquitination of ECSIT at residue $\mathrm{K} 372$ is critical for NF- $\mathrm{kB}$ binding activity and its translocation to the nucleus (Wi et al., 2014). Experimental evidence shows that the $\mathrm{N}$-terminal region of ECSIT comprising residues 200-260 co-purifies with TRAF6 (Wi et al., 2014) suggesting that the ECSIT PPR domain might be involved in TRAF6-specific binding (Figure 3B). The C-terminal region of ECSIT (residues 260-431) specifically binds to the TGF-beta-activated kinase 1 (TAK1; Wi et al., 2014), which could indicate that the $\mathrm{PH}$ domain plays a role in the ECSITTAK1 binding to induce the activation of NF-kB-dependent gene expression (Supplementary Figure 2).

Mitochondrial ECSIT participates in CI assembly (Supplementary Table 2; Vogel et al., 2007a; Nouws et al., 2010; West et al., 2011). The knockdown of ECSIT in human cells reduces the levels of NDUFAF1 and results in impaired CI assembly and activity (Vogel et al., 2007a). In fact, the mitochondrial isoform of ECSIT was found in $500-600-\mathrm{kDa}$ and $830-\mathrm{kDa}$ assembly intermediates of $\mathrm{CI}$ and associated with NDUFAF1 (Vogel et al., 2007a). Furthermore, knockdown of ECSIT in cells results in disturbed mitochondrial function, supporting a role for ECSIT in linking the assembly of oxidative phosphorylation complexes with the inflammatory response (Vogel et al., 2007a).

\section{ACAD9}

Acyl-CoA dehydrogenase 9 (ACAD9) is a 621 amino acid protein with an N-terminal MTS, three Acyl-CoA dehydrogenase domains, two conserved ACAD motifs and a potential $\mathrm{N}$-glycosylation site (Figure 4A, Supplementary Figure 3). ACAD9 undergoes a mitochondrial processing, resulting in the cleavage of the first 37 amino acids from the precursor protein and leaving residue $\mathrm{A} 38$ as the $\mathrm{N}$-terminal amino acid of the mature form of the enzyme (Figure 4). The ACAD family comprises mitochondrial flavoenzymes that catalyze the initial rate-limiting step of the fatty acid $\beta$-oxidation, which is one of the main energy-producing metabolic pathways in eukaryotes.
While different dehydrogenases target fatty acids of varying chain length, all ACADs are mechanistically similar and use FAD as a required co-factor in addition to the presence of an active site glutamate in order for the enzyme to function. ACAD9 is very similar to its ancestor, the very long-chain acyl-CoA dehydrogenase (VLCAD), sharing 47\% sequence identity and 67\% similarity (Nouws et al., 2010). ACAD9 was originally annotated in vertebrates as a result from VLCAD gene duplication. However, it is has also been found in non-vertebrate metazoa (Elurbe and Huynen, 2016). The amino acid sequence of ACAD9 contains the two conserved dehydrogenase signatures (Supplementary Figure 3) and an important active site residue (E426; Figure 4A). These features confer some residual acyl dehydrogenase activity, suggesting that the enzymatic activity is a rudiment of the VLCAD gene duplication event (Nouws et al., 2014). However, unlike VLCAD, ACAD9 seems critical for oxidative phosphorylation (Nouws et al., 2014) and plays a key role as a CI assembly factor, as shown by different approaches (Nouws et al., 2010). Indeed, it binds ECSIT and NDUFAF1 (Supplementary Table 3) and mutations on ACAD9 cause CI deficiencies (Table 2; Nouws et al., 2014). Knockdown of ACAD9, NDUFAF1, or ECSIT in cultured cells determines the decrease of all three proteins and of CI holo-complex as well (Gerards et al., 2011).

A homology model of the structure of an ACAD9 dimer based on the VLCAD crystal structure is shown in Figure 4B (Nouws et al., 2010). Unlike other ACADs, human VLCAD, and ACAD9 contain an extension of the C-terminus that has been suggested to be involved in intra-mitochondrial membrane binding (Swigonova et al., 2009). The homodimer model further indicates that sequence differences in ACAD9 are associated with two solvent exposed 35 amino acid-long $\alpha$-helices, which might represent a new interaction domain important for its acquired role in respiratory complex assembly in vertebrates (Supplementary Table 3, Figure 4C; Nouws et al., 2010; Scheffler, 2010; Mick et al., 2012). Interestingly, this region is predicted to be a high-confidence protein binding site (Buchan et al., 2013; Figure 4B). Furthermore, although the role of the FAD cofactor in $\mathrm{CI}$ assembly is unclear, it may function as a chemical chaperone and improve specific ACAD9 folding (Nouws et al., 2014).

\section{TMEM126B}

Transmembrane protein 126B (TMEM126B) is an integral component of the inner mitochondrial membrane and comprises 230 residues folded in 4 transmembrane $\alpha$-helices (Heide et al., 2012). TMEM126B is found exclusively in mammals and likely resulted from a segmental duplication of TMEM126A, an inner mitochondrial membrane protein of unknown function (Elurbe and Huynen, 2016). Although the molecular function of TMEM126B has not been clarified yet, it has been recently discovered that it is required for the CI assembly (Supplementary Table 4; Heide et al., 2012). One of the critical functions of this membrane protein might be the recruitment of the hydrophilic MCIA components to constitute a functional MCIA complex (Vartak et al., 2014). Indeed, NDUFAF1, ECSIT, and ACAD9 are not recruited to the membrane in case of lack of TMEM126B, leading to an MCIA complex misassembly (Vartak et al., 2014). 
A

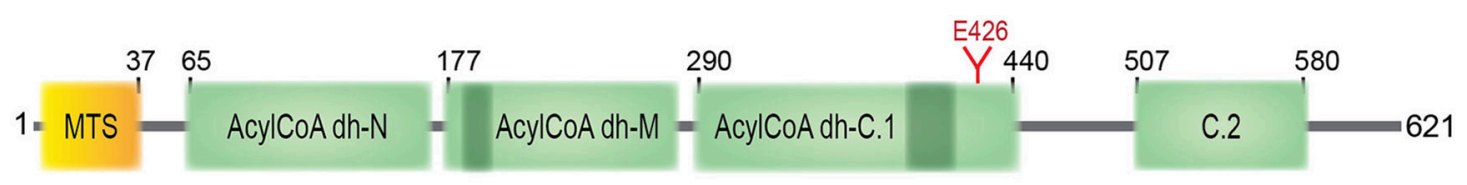

B

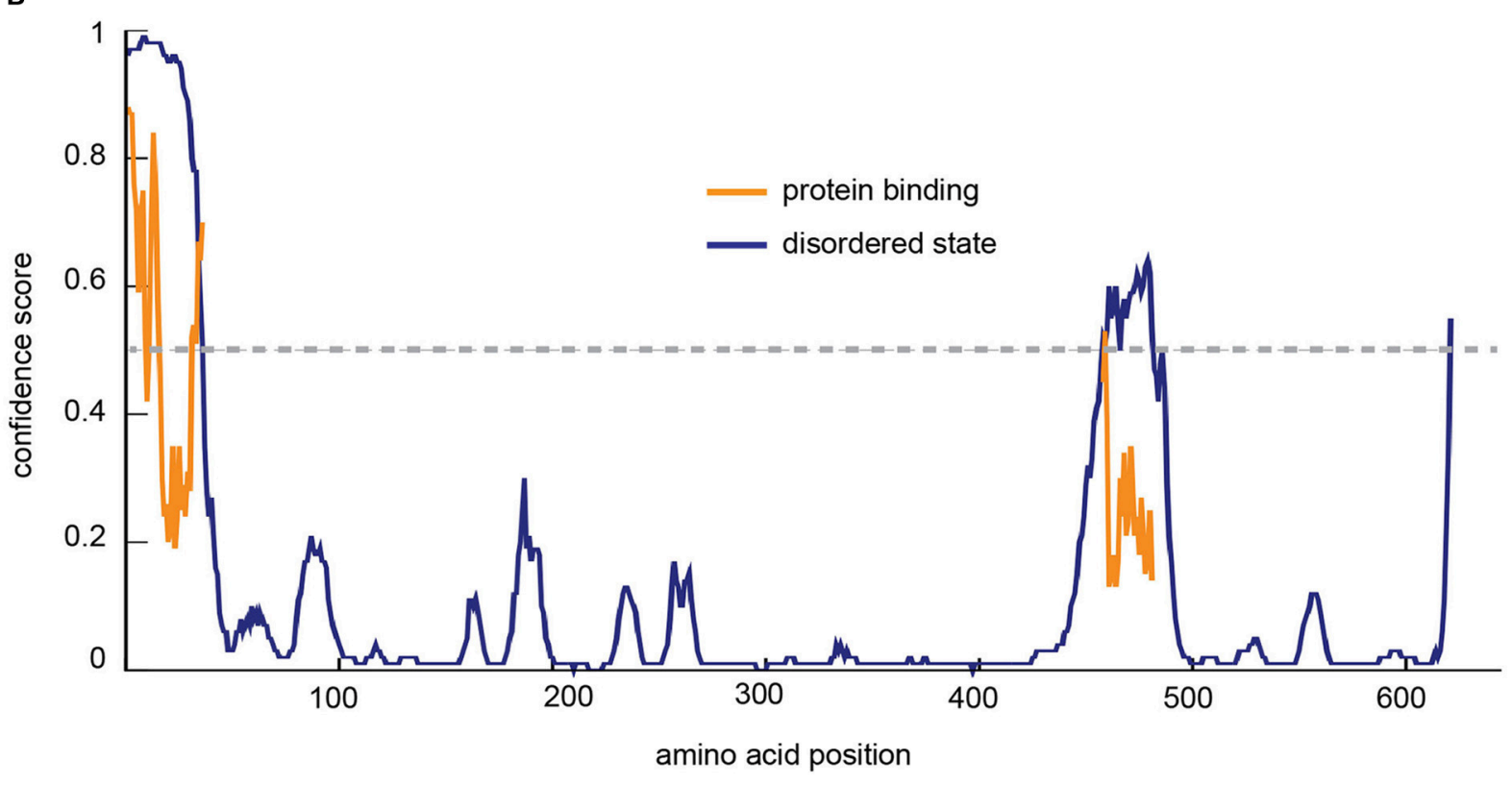

C

\begin{tabular}{|c|c|c|}
\hline $2 U X W$ & & $-\alpha 12$ \\
\hline & &  \\
\hline & & CEEG \\
\hline XACAD9 & 384 & $\mathrm{FE}$ \\
\hline 9 & 393 & Q \\
\hline D & 420 & GCM \\
\hline & & EGSEZZMWKVTDECIQIMGGMGFMKE PGVERLRDLRIFRIFEGTNDILRLFVALQGC \\
\hline
\end{tabular}

$2 U \times W$

$$
\alpha 14
$$

Co

hACAD9 443 HAGRILTTRIHELKQ--AKVSTVMDTVGRRLRDSLGRTVDLGLTGNHGVVHPSLADSANK

mACAD9 447 HAGRILTSRIKELKS--GNVTTVMETIGRKLRDSLGRTVDLGLTGDLGVVHPSLGDSANK

XACAD9 444 HAGKILIGKIKEMKK--GNVGVAMELF FKKLRDSMGRNVNLGLIGNEGVVHPSLEESAKK

dACAD9 453 HZGKILTGKIKEMKK--GNLGVVEEILGKKIKDTV-QTZDFGLTGKDGVVHPSLTESAKM

mVLCAD 480 DKGKELTGLGNZLKNPFGNVGLLMGEAGKOLRR---RTGIGSGLSLSGIVHPELSRSGEL

hVLCAD 479 DKGKELSGLGSALKNPFGNIAGLILGEZGKQLR----RAGLGSGLSLSGLVHPELSRSGEL

\begin{tabular}{|c|c|c|}
\hline & & \multirow{2}{*}{$\alpha 15 \quad \alpha 16$} \\
\hline \multicolumn{2}{|l|}{$2 U X W$} & \\
\hline hACAD9 & 501 & FEENTYCFGRTVETLILRFGKT IMEEQLVLKRVANILINLYGMTAVLSRASRSIRIGLRN \\
\hline & 505 & - \\
\hline & & \\
\hline & & \\
\hline VL & & 18 \\
\hline & & LIQRLADGAIDLYAMVVVLSRASRSLSEGHP \\
\hline
\end{tabular}

FIGURE 4 | ACAD9 protein domain organization. (A) Human ACAD9 domain organization. MTS: mitochondrial signal peptide (residues 1-37). It contains three Acyl-CoA dehydrogenase/oxidase domains based on InterPro server (Mitchell et al., 2015): N-terminal (residues 65-175, ID:IPR013786); central (residues 177-277, 


\section{FIGURE 4 | Continued}

ID:IPR006091); and a C-terminal split into two subdomains (C.1. residues 290-440 and C.2. 507-580, ID:IPR009075). Acyl-dehydrogenase catalytic residue E426 is shown in red. (B) Prediction of disorder tendency of the full-length ACAD9 with PSIPRED server (Buchan et al., 2013). High-confidence protein binding sites are shown in orange lines. (C) Multiple alignment of ACAD9 and VLCAD (highlighted in pink) orthologues around ACAD9 residues 383 to 561 , based on CLUSTALX (Larkin et al., 2007) and edited with BioEdit (Hall, 2011). This regions shows the highest sequence variability between ACAD9 and VLCAD homologs and is predicted to correlate with the folding of an external 35 residue helix (shown in gray) that seems to be absent in the VLCAD crystal structure (PDB code 2 UXW, McAndrew et al., 2008) and which might represent a specific interaction domain site unique for ACAD9. Residue numbering according to human ACAD9 sequence. h, human; m, mouse; x, African frog; d, zebrafish.

TABLE 2 | Currently identified pathological mutations in $\mathrm{Cl}$ assembly factors causing CID.

\begin{tabular}{|c|c|c|c|c|}
\hline Assembly factors & UniProt entries & Annotated mutations & Disease phenotypes & References \\
\hline NDUFAF1 & Q9Y375 & H92R, T207P, K253R, R211C, G245R & LS, L, HC & $\begin{array}{l}\text { Dunning et al., 2007; Fassone et al., 2011; Dewulf } \\
\text { et al., } 2016\end{array}$ \\
\hline NDUFAF2 & Q8N183 & $\begin{array}{l}\text { M1L, W3 }{ }^{\text {STOP }} \text {, Y38 STOP, R45STOP, } \\
\text { W74 }{ }^{\text {STOP }} \text {, I35Sfs } \times 17^{a}, \text { A73GfsX5a }\end{array}$ & LS, L & $\begin{array}{l}\text { Ogilvie et al., 2005; Barghuti et al., 2008; Hoefs } \\
\text { et al., 2009; Janssen et al., 2009; Calvo et al., 2010; } \\
\text { Herzer et al., 2010; Ghaloul-Gonzalez et al., } 2016\end{array}$ \\
\hline NDUFAF3 & Q9BU61 & M1T, G77R, R122P & FLA & Saada et al., 2009 \\
\hline NDUFAF4 & Q9P032 & L65P & LS, L & Saada et al., 2009 \\
\hline NDUFAF5 & Q5TEU4 & L159F, L229P & LS & Sugiana et al., 2008; Gerards et al., 2010 \\
\hline NDUFAF6 & Q330K2 & Q99R & LS, L & Pagliarini et al., 2008 \\
\hline NDUFAF7 & Q7L592 & n.d. & n.d. & \\
\hline FOXRED1 & Q96CU9 & Q232STOP, R352W, V421M, N430S & LS, L & $\begin{array}{l}\text { Calvo et al., 2010; Fassone et al., 2011; Zurita } \\
\text { Rendón et al., } 2014\end{array}$ \\
\hline NUBPL & Q8TB37 & $\begin{array}{l}\text { G56R, D105Y, L193F, E223AfsX4a } \\
\text { 240-kb deletion (exons 1-4); 137-kb } \\
\text { duplication (exon 7) }\end{array}$ & LS, L & $\begin{array}{l}\text { Calvo et al., 2012; Tucker et al., 2012; Kevelam } \\
\text { et al., } 2013\end{array}$ \\
\hline TMEM126B & Q8IUX1 & G212V, N134lfsX2a & CID & Alston et al., 2016 \\
\hline ACAD9 & Q9H845 & $\begin{array}{l}\text { F44I, E63STOP, F120SfsX9a , R127Q, } \\
\text { A170V, G172R, S268F, T243R, } \\
\text { R266Q/W, L314P, A326P, F339V, } \\
\text { E413K, R414S, R417C, R433Q, } \\
\text { R469W, R518C, R532W/Q, V546L, } \\
\text { L558PfSX45a , H563A }\end{array}$ & LS, L, HC & $\begin{array}{l}\text { Scholte et al., 1995; Haack et al., 2010; Nouws } \\
\text { et al., 2010; Gerards et al., 2011; Collet et al., 2016; } \\
\text { Dewulf et al., 2016; Leslie et al., 2016; Pronicka } \\
\text { et al., } 2016\end{array}$ \\
\hline ECSIT & Q9BQ95 & n.d. & n.d. & \\
\hline TIMMDC1 & Q9NPL8 & n.d. & n.d. & \\
\hline
\end{tabular}

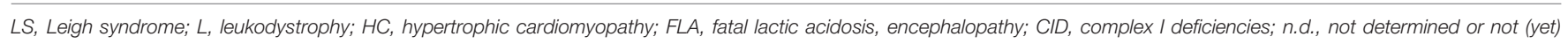
associated with disease.

${ }^{a} f S=$ frameshift.

Furthermore, depletion of TMEM126B leads to accumulation of the Q module-ND1 intermediate (Guarani et al., 2014) and severely impairs mitochondrial respiration (Heide et al., 2012).

\section{TIMMDC1}

The translocase of inner mitochondrial membrane domaincontaining 1 (TIMMDC1) protein contains 285 residues embedded in four transmembrane $\alpha$-helices. It belongs to the TIM17-TIM22-TIM23 (translocases of the inner mitochondrial membrane) domain family, which are membraneembedded multi-protein complexes that mediate the transport of nuclear-encoded proteins across and into inner mitochondrial membranes (Kurz et al., 1999; Chacinska et al., 2005). Recent data show that the transmembrane protein TIMMDC1 is also physically associated with the MCIA complex and functions in CI assembly (Supplementary Table 5; Guarani et al.,
2014). Depletion of TIMMDC1 in tissue culture cells leads to accumulation of CI subcomplexes similar to MCIA factor depletion effects, resulting in impaired CI activity and cellular respiration and a decreased stability of several CI subunits (Guarani et al., 2014).

\section{The Molecular Assembly of the MCIA Complex}

Overall, the available data show that depletion of the MCIA factors NDUFAF1, ECSIT, or ACAD9 leads to the accumulation of the $370-\mathrm{kDa}$ assembly intermediate from the CI membrane arm, which contains mtDNA-encoded subunits with about 20 transmembrane $\alpha$-helices (Andrews et al., 2013). How the MCIA factors function is not known yet, but they may stabilize this subcomplex and promote its incorporation to the 
other subcomplexes to build up the complete holo-enzyme. However, the MCIA complex could also have a more general function, regulating CI assembly at the translation level by the induction and stabilization of the transcripts of mtDNA-encoded subunits when required (Supplementary Tables 2-5). The fact that the sequential assembly pathway of MCIA factors is still incomplete suggests that additional extrinsic and/or intrinsic assembly factors remain to be identified (Table 1; Andrews et al., 2013).

The homology model of ACAD9 dimer provides initial insights into the molecular assembly of the MCIA complex (Figure 5). In a first step, the newly proposed interaction domain of ACAD9 homodimer could bind to ECSIT and NDUFAF1, respectively, forming a tetrameric complex that would then interact with the membrane assembly factor TMEM126B to anchor the MCIA complex onto the membrane (Nouws et al., 2010). Indeed, it has been suggested that TMEM126B would insert hydrophobic proteins into the $370-\mathrm{kDa}$ subcomplex to subsequently associate with the $315-\mathrm{kDa}$ subassembly and to finally constitute a subcomplex of $550 \mathrm{kDa}$ (Andrews et al., 2013). Furthermore, TIMMDC1 could be involved in the transfer of newly imported nuclear-encoded subunits and
MCIA factors as well, similarly to the other family member TIM21 in CIV assembly (Mick et al., 2012). TIMMDC1 would then engage with assembly factors after import and, as it has been recently speculated, it would also function as a membrane anchor to assemble additional components of the MCIA complex, together with both the $\mathrm{Q}$ module components and the major membrane arm, and to organize intermediates into a productive assembly pathway (Guarani et al., 2014). During the final stages of CI assembly, these factors would dissociate, since these proteins are not found associated with the mature holo-enzyme (Mckenzie and Ryan, 2010).

Nonetheless, considering that protein disorder prediction algorithms are not $100 \%$ accurate, especially for transmembrane topology prediction (Buchan et al., 2013), experimental data are essential for a complete understanding of the MCIA complex assembly and the underlying molecular mechanisms of the CI assembly process at the structural level. The development of reconstituted systems at high resolution by $\mathrm{X}$-ray crystallography or electron microscopy will thus enable to unravel the protein complex organization down to the atomic detail.

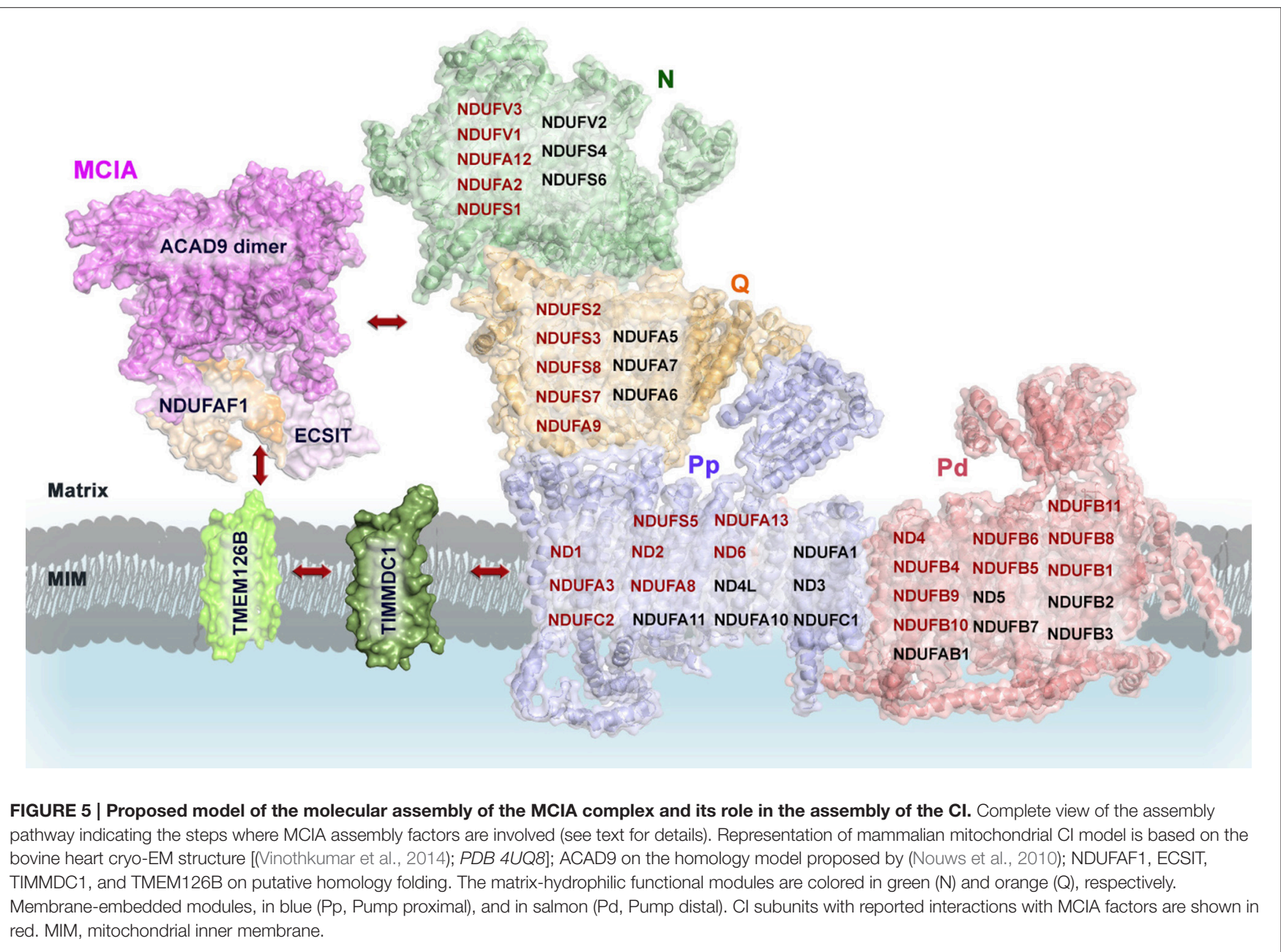




\section{DEFECTS IN COMPLEX I ASSEMBLY RESULT IN NEURODEGENERATIVE DISEASES}

As described earlier, CI acts as metabolism hub essential in cellular energy production, but it is also the major source of ROS production. Redox signals can mediate through cysteine oxidation, namely S-oxidation, S-glutathionylation, and Snitrosylation, which have been shown to also regulate CI activity (Bak and Weerapana, 2015; Mailloux, 2015). Hence, even subtle defects in CI assembly or function are directly linked to oxidative stress and ultimately to mitochondrial dysfunction and disease. When ROS production overwhelms the endogenous antioxidant systems this can lead to oxidative damage in mtDNA, membranes or proteins, impairing cellular functions such as ATP and heme synthesis, fatty acid oxidation, or the urea and tricarboxylic acid cycles. Mitochondrial ROS damage can also lead to cytochrome- $c$ release to the cytosol by mitochondrial outer membrane permeabilization and thereby trigger apoptosis through the activation of the caspase cascade (Jeong and Seol, 2008). Neuronal cells are particularly susceptible to ROS-induced damage because they mainly rely on oxidative metabolism for ATP generation, in contrast to glial cells, which are highly glycolytic (Belanger et al., 2011). However, there are metabolic interactions from astrocytes to neurons that appear to play an important role in the control of neuronal activity and excitability (Belanger et al., 2011).

Mitochondrial integrity also declines as a consequence of aging. Interestingly, some of the functional impairments seem to be correlated with increasing oxidative stress derived from defects in the OXPHOS system. Furthermore, agerelated neurodegenerative diseases (NDs) may exacerbate the oxidative damage. Indeed, mitochondrial dysfunction represents a common pathogenic mechanism in NDs like Alzheimer's disease (AD), Parkinson's disease (PD), amyotrophic lateral sclerosis, Huntington's disease, and prion diseases (Beal, 2002; Lin and Beal, 2006; Tillement et al., 2011; Federico et al., 2012; Schapira, 2012; Butterfield et al., 2016). In particular, CI activity is reduced with aging, as demonstrated in primate brains and in long-lived mice models (Bowling et al., 1993; Miwa et al., 2014). Typically, genetic defects in CI and its assembly factors account for a heterogeneous group of fatal disorders collectively known as complex I deficiencies (CID). However, recent clinical and experimental studies also indicate a possible link between $\mathrm{CI}$ dysfunction and the pathogenesis of $\mathrm{AD}$ or $\mathrm{PD}$, which have accelerated the interest toward investigations into CI biology as a promising therapeutic target for NDs (Eckert et al., 2010; Winklhofer and Haass, 2010).

\section{Neurodegeneration Associated with Complex I Deficiencies}

CID is the most prevalent genetic defect in mitochondrial energy metabolism, accounting for approximately a third of the OXPHOS disorder cases (Kirby et al., 1999). CID is characterized by marked genetic, tissue, and organ specific heterogeneity with often overlapping clinical phenotypes. The majority of the affected patients also presents Leigh syndrome (LS): a fatal, incurable, rapidly progressive neurodegenerative disorder typically occurring within the first weeks/months after birth and with an incidence of at least 1 case out of 40,000 live births (Darin et al., 2001). Neuropathologically, LS features bilateral symmetrical necrotic lesions characterized by spongiosis, neuronal loss, astrocytosis, and capillary proliferation; clinical signs and symptoms include muscular hypotonia, developmental delay, abnormal eye movements, respiratory abnormality, seizures, and ataxia (Leigh, 1951; Rahman et al., 1996). Additional CID clinical phenotypes have been associated with other childhood ND, including Leighlike syndrome, leukoencephalopathy, MELAS (mitochondrial encephalomyopathy, lactic acidosis and stroke-like episodes), and NARP (neuropathy, ataxia and retinitis pigmentosa) syndromes (Fassone and Rahman, 2012; Koopman et al., 2016).

Mutations in six mtDNA-encoded (ND1 to 6) and thirteen nuclear-encoded (NDUFS1 to 8; NDUFV1; NDUFA1, 2, 9, 10, and 12) CI subunits have been correlated to LS (Rodenburg, 2016). Early investigations on CID patient-derived fibroblasts showed partial or incomplete CI assembly and diminished catalytic activity (Verkaart et al., 2007a), which was inversely correlated with ROS production in mitochondria-enriched fractions (Koopman et al., 2007; Verkaart et al., 2007b). In addition, CID patient fibroblasts showed a significantly depolarized mitochondrial membrane, which in turn caused a dramatic effect on ATP production and protein transport across mitochondrial membranes (Komen et al., 2007; Distelmaier et al., 2009a,b). Finally, aberrations in CI activity have an impact in the calcium homeostasis, a crucial stimulus for activating ATP production via OXPHOS, as observed in CID derived cells (Willems et al., 2008). Nevertheless, while much progress has been made in elucidating the structure of mammalian $\mathrm{CI}$, the molecular mechanisms underlying CID are still poorly understood.

Moreover, clinical studies have reported that only about 33\% of the CID cases are associated with specific genetic defects in the $44 \mathrm{CI}$ subunits (Calvo et al., 2010), revealing that assembly factors may account for the remaining CID cases (Nouws et al., 2012). Interestingly, the first evidence of the role of assembly factors in CID comes from the identification of pathological mutations in genes encoding for MCIA components and other CI assembly factors, most of them linked to CID but with an additional broad spectrum of disease phenotypes, such as LS, leukodystrophy, MELAS and NARP syndromes (Table 2; Nouws et al., 2012; Rodenburg, 2016; Wu et al., 2016). Along this line, several ACAD9 mutations are associated to CID (Haack et al., 2010; Rodenburg, 2016) and indeed, stabilization of ACAD9 might represent a therapeutic approach for treating CID, as shown by a riboflavin treatment (the central component of FAD cofactors) where CI activity increased and clinical conditions of ACAD9-defective patients improved (Gerards et al., 2011). Some other MCIA factors may display a pleiotropic role in cells, such as ECSIT, which was identified as an inter-pathway protein node interacting with $A \beta$-producing enzymes (Soler-Lopez et al., 2011), suggesting a link between $\mathrm{CI}$ assembly/stability and $\mathrm{AD}$ pathogenesis. Upon inflammation 
or $\mathrm{A} \beta$ insult, ECSIT may expand the signaling of the immune response to the inner-mitochondrial level, e.g., by stabilizing CI to ensure mitochondrial physiology, or induce apoptosis when repair failure (Soler-Lopez et al., 2012). Recently, two biallelic mutations have been identified in TMEM126B, which cause CID with a broad disease phenotype. Interestingly, patient-derived cell lines show markedly CI assembly defects (like accumulation of intermediates) and decreased levels of the remaining MCIA components: ECSIT, ACAD9, and NDUFAF1 (Alston et al., 2016).

Notably, recent investigations have revealed that around $40 \%$ of CID cases are not associated with mutations in CI subunit or assembly factor encoding genes, suggesting that other yet unknown factors may affect the proper function of the ETC (Taylor et al., 2014). These findings have prompted the interest toward the identification of novel assembly factors in order to provide a genetic explanation and potential therapeutic strategies for those CID cases not directly linked to CI subunit mutations. To achieve this goal, genome-wide sequencing, proteomic and structural approaches will be highly relevant in the identification and characterization of CID-associated genes whose physiological roles are still undetermined.

\section{Complex I Dysfunction and Parkinson's Disease}

CI dysfunction also seems to be critical in PD pathogenesis, correlated with the degeneration of dopaminergic neurons in the substantia nigra pars compacta (Schapira et al., 1990; David et al., 2005; Keeney et al., 2006; Gatt et al., 2016). One of the PD pathological hallmarks is the presence of intracellular inclusions called Lewy bodies that consist of aggregates of the presynaptic protein $\alpha$-synuclein (Dawson and Dawson, 2003). Besides $\alpha$ synuclein, several proteins have also been associated with PD, some of which (e.g., DJ-1, PINK1, Parkin, HTRA2) localize in the mitochondria and gain toxic functions due to mutations that may lead to mitochondrial dysfunction (Federico et al., 2012). In fact, CI defects and increased oxidative damage are consistent features of both sporadic (idiopathic) and familial (genetic) PD forms. Decrease of CI activity has been reported in the substantia nigra and in the cortex of PD patients (Haelterman et al., 2014).

Early experiments studying CI induced inhibition by agrochemicals, such as rotenone or 1-methyl-4-phenyl-1,2,3,6tetrahydropyridine (MPTP), showed a correlation with PD symptoms like the formation of $\alpha$-synuclein containing inclusions, bioenergetics defects and ROS overproduction (Liang et al., 2007; Sherer et al., 2007). Although it is plausible that a chronic exposure to CI inhibitors might contribute to the development of sporadic PD, it is unlikely that toxin exposure accounts for $\mathrm{CI}$ defects in the general population. An alternative hypothesis proposes that inherited or somatic mutations in mtDNA might account for CI defects triggering oxidative stress and PD, experimentally supported by PD cytoplasmic hybrid (i.e., cybrid) cell lines showing higher ROS levels (Swerdlow et al., 1996; Gu et al., 1998). Different studies have reported somatic mutations in ND4 and ND5 CI subunits in PD patients (Simon et al., 2004; Parker and Parks, 2005). Furthermore, $\alpha$-synuclein contains an MTS that enables an eventual translocation to the inner mitochondrial membrane (Martin et al., 2006). How mitochondrial localization of $\alpha$-synuclein affects mitochondrial function in human brain has not been addressed in detail, although independent observations propose a role for $\alpha$ synuclein in maintaining the OXPHOS physiological functions (Ellis et al., 2005; Devi et al., 2008). In transgenic (tg) mice, over-expression of $\alpha$-synuclein impairs mitochondrial function, increases oxidative stress and enhances the substantia nigra pathology induced by MPTP (Song et al., 2004). Interestingly, in vivo data using human fetal dopaminergic primary neuronal cells and PD brain-derived tissues (striatum and substantia nigra) have shown a progressive accumulation of $\alpha$-synuclein in the mitochondria resulting in impaired CI functioning and increased oxidative stress. Remarkably, $\alpha$-synuclein has been found in direct association with the $\sim 600-\mathrm{kDa}$ subcomplex and the holo-CI in mitochondria derived from PD patients (Devi et al., 2008). These results suggest that $\alpha$-synuclein accumulation in the mitochondrial matrix may also affect the proper assembly of CI and lead to mitochondrial dysfunction. Other studies have shown that some core (ND4, ND5, NDUFS1, NDUFS2, and NDUFV1) and accessory (NDUFB5, NDUFB6, and NDUFB7) subunits are oxidatively damaged in PD brains, resulting in CI misassembling and functional impairment (Keeney et al., 2006).

Overall, these findings support the assumption that CI misassembly may play a role in $\mathrm{PD}$ onset and progression. However, the molecular mechanisms contributing to the instability of CI assembly, loss of bioenergetic functions and oxidative stress are yet unclear. It is tempting to speculate that abnormal $\alpha$-synuclein accumulation in mitochondria, mutations, or polymorphisms in $\mathrm{PD}$-associated mitochondrial genes may lead to defects in the CI assembly process, which eventually plays a central role in PD pathology.

\section{Complex I Dysfunction and Alzheimer's Disease}

$\mathrm{AD}$ is the most prevalent form of $\mathrm{ND}$, characterized by a progressive memory loss and impairment of cognitive abilities (Duyckaerts et al., 2009; Hyman et al., 2012). At the neuropathologic level, it reveals the presence of amyloid plaques and neurofibrillary tangles (NFT) as the final result of misfolding and aggregation of amyloid- $\beta(A \beta)$ and tau proteins. $A \beta$ is the cleavage product of a much larger protein, the Amyloid Precursor Protein (APP), by $\alpha-, \beta$-, and $\gamma$-secretases (Selkoe, 2001). Although different $A \beta$ truncated species can be generated during the cleavage process (Willem et al., 2015), $A \beta_{1-42}$ (i.e., the 42-amino acid form of $\mathrm{A} \beta$ ) is the most neurotoxic peptide and represents the majority of $A \beta$ deposits in $A D$ brain (Welander et al., 2009). A $\beta$ deposition leads to the formation of plaques in neuronal (neurites and synaptic terminals) and glial (astrocytes and microglia) cells. NFTs are intracellular aggregates of abnormal hyper-phosphorylated tau that form cytoplasmic fibrils (Braak et al., 1994). While the neurotoxicity of $\mathrm{A} \beta$ and tau misfolding, aggregation and spreading have been deeply investigated, much less is known about the early molecular events underlying $\mathrm{AD}$ pathogenesis. Intraneuronal $\mathrm{A} \beta$ 
accumulation has emerged as one of the main causative effects of synaptic damage and cognitive decline in $\mathrm{AD}$ (LaFerla et al., 2007). According to the AD mitochondrial hypothesis, defects in mitochondrial metabolism and particularly in the ETC may play a role during the early stage of $\mathrm{AD}$ pathogenesis (Valla et al., 2001). $A \beta$ has been detected in mitochondria from both tg mice and murine cell lines expressing human mutant APP, displaying increased ROS production, decreased cytochrome oxidase activity, morphological mitochondrial alteration, and apoptosis (Manczak et al., 2006; Cha et al., 2012). Furthermore, $\mathrm{A} \beta$ has also been associated with mitochondria from $\mathrm{AD}$ patients, showing mitochondrial fragmentation in various brain regions (Reddy et al., 2010). As extensively reviewed, $A \beta$ accumulation in the mitochondria leads to different mitotoxic events, such as permeabilization of membranes, reduction of respiratory function, and disturbance of the mitochondrial calcium homeostasis (Swerdlow et al., 2010; Moreira et al., 2010a; Tillement et al., 2011). Among these mechanisms, impaired OXPHOS functions have been frequently observed in $\mathrm{AD}$ patients and in different $\mathrm{AD}$ tg mouse and cellular models (Hroudova et al., 2014).

Clinical investigations have reported impairment of CI activity and reduced level of its subunits in multiple zones of post mortem AD brains (Mutisya et al., 1994; Aksenov et al., 1999; Kim et al., 2000, 2001), as well as in other tissues such as platelets (Cardoso et al., 2004). A number of proteomic studies on AD tg mouse models have provided clear evidence of the involvement of $A \beta$ and tau proteins in CI defects and consequent mitochondrial dysfunction (David et al., 2005; Rhein et al., 2009; Chou et al., 2011; Zhang et al., 2015). Interestingly, tg mice overexpressing the tau P301L mutation (i.e., causing hyperphosphorylated tau accumulation and NFT) exhibit reduced CI activity and, with age, impaired mitochondrial respiration and ATP synthesis. Furthermore, isolated cortical brain cells from this mouse model display modified lipid peroxidation, increased ROS production and altered mitochondrial membrane potential after $A \beta$ insults (David et al., 2005). This finding has led to propose a tau and $A \beta$ synergistic contribution to mitochondrial pathology by inhibiting ETC -particularly CI- and inducing ROS-derived apoptosis. Consistent with this hypothesis, deregulation of $\mathrm{CI}$ and CIV has also been observed in triple-tg $\mathrm{AD}$ mice, (coexpressing AD-linked mutations in presenilin 2, APP, and tau proteins; Rhein et al., 2009). Importantly, in 8-month old tg mice (i.e., prior the appearance of the disease symptoms) deregulation of CI seems to be tau-dependent, whereas that of $\mathrm{CIV}$ is $\mathrm{A} \beta$-dependent. However, with aging and especially in the presence of both $A \beta$ plaques and NTF, defects on CI and CIV become more marked resulting in a significant decrease of respiratory parameters, reduced mitochondrial membrane potential and increased ROS level, providing further evidence to a synergistic detrimental effect of $\mathrm{A} \beta$ and tau on ETC (Rhein et al., 2009). Furthermore, in support of the central role of $\mathrm{CI}$ in $\mathrm{AD}$ pathogenesis, recent data suggest that $\mathrm{CI}-$ derived ROS contributes to amyloidogenic APP processing (Leuner et al., 2012; Tamagno et al., 2012; Bobba et al., 2013). Taken together, $A \beta$ - or tau-mediated CI impairment result in a vicious cycle inducing electron leakage from the ETC leading boosting mitochondrial dysfunction and oxidative stress. Notably, pathological mechanisms underlying AD pathogenesis share common features with LS and the other CID forms previously described. A link between CID and AD has been recently established with the identification of a naturally occurring mutation, S339G, in the ND4 core subunit of CI of a premature aging mouse strain, SAMP8 (Imanishi et al., 2011). SAMP8 mice develop early learning and memory deficits together with other characteristics similar to those seen in $\mathrm{AD}$, including ROS overproduction and $\mathrm{A} \beta$ plaques with aging (Morley et al., 2000, 2012). Interestingly, an adjacent human mutation, $\mathrm{R} 340 \mathrm{H}$, in the ND4 gene also results in CID with associated LS, Leber hereditary optic neuropathy and late onset MELAS syndrome, characterized by increased ROS production and altered CI assembly (Wong et al., 2002; Deschauer et al., 2003), prompting a new investigative field for the development of therapeutic approaches targeting mitochondria for the treatment of $\mathrm{AD}$ and CID (Friedland-Leuner et al., 2014).

\section{PERSPECTIVES IN MITOCHONDRIAL NEUROBIOLOGY}

Emerging evidence suggest a pivotal role of mitochondrial dysfunction in the pathogenesis of major neurodegenerative disorders. In particular, CID is the most common OXPHOS disorder in humans and defects in CI assembly process are often detected. From a clinical point of view, mitochondrial biology holds the promise to provide novel insights into the pathogenesis of several NDs. Different proteomic investigations on mitochondrial proteins differentially expressed in CID (Pagliarini et al., 2008; Alston et al., 2016), AD (Sultana et al., 2011), and PD (Henchcliffe and Beal, 2008) suggest that proteins involved in CI assembly and functioning might be novel targets for biomarker identification, disease progression and ultimately, therapeutic approaches. Several drug discovery studies are under development to boost mitochondrial health or tune up the mitochondrial power engine to compensate for damaged or interrupted neuronal power failure upon neuronal stress (Moreira et al., 2010b). Novel therapeutic strategies will thus enable mitochondria to better cope with oxidative stress, excitotoxicity, and other neuronal stresses, as well as maintain efficient respiratory function in neurons. However, the drugs tested in most of the current trials do not target mitochondria but monitor mitochondrial function as an indicator of indirect effects of the treatments (Wang et al., 2016). There is increasing evidence that a fully assembled and stable CI is key in various pathways. Therefore, a better understanding of the regulatory mechanisms underlying $\mathrm{CI}$ assembly will unveil how mitochondria malfunction affects metabolic reprogramming and neuronal integrity. To this end, the molecular characterization of existing and novel assembly factors emerges as a promising approach for mitochondria-targeted therapeutics, the so-called mitochondrial medicine (Weissig et al., 2004), and for specific discrimination among ND disorders, with CI assembly factors gaining a new and exciting dimension. 


\section{CONCLUSIONS}

Despite the critical importance of CI in energy production and disease, many aspects of its assembly and activity are still poorly understood, since they require a stepwise coordination of different processes and components that are tightly interconnected. Clinical data have enabled the identification of CI subunits and assembly factors implicated in neurodegeneration, but they provide a limited understanding. Furthermore, other yet unknown factors may be involved in the proper function of the ETC. In this review, we have presented the current knowledge of CI structure and its assembly factors, with a particular focus on neurodegenerative disorders. Pathological mutations in CI assembly factors seem to affect the functional integrity of the holo-enzyme, although they have not been investigated at the molecular level yet. Therefore, structural studies on such proteins together with in vivo experiments will help us to elucidate the dynamics of CI biogenesis and will thus contribute to a better understanding of the altered mitochondrial pathways involved in neuronal death. These efforts will provide unique insights and will have a major contribution in the quest for novel disease-modifying

\section{REFERENCES}

Aksenov, M. Y., Tucker, H. M., Nair, P., Aksenova, M. V., Butterfield, D. A., Estus, S., et al. (1999). The expression of several mitochondrial and nuclear genes encoding the subunits of electron transport chain enzyme complexes, cytochrome c oxidase, and NADH dehydrogenase, in different brain regions in Alzheimer's disease. Neurochem. Res. 24, 767-774. doi: 10.1023/A:1020783614031

Alston, C. L., Compton, A. G., Formosa, L. E., Strecker, V., Oláhová M., Haack, T. B., et al. (2016). Biallelic mutations in TMEM126B cause severe complex i deficiency with a variable clinical phenotype. Am. J. Hum. Genet. 99, 217-227. doi: 10.1016/j.ajhg.2016.05.021

Andrews, B., Carroll, J., Ding, S. J., Fearnley, I. M., and Walker, J. E. (2013). Assembly factors for the membrane arm of human complex I. Proc. Natl. Acad. Sci. U.S.A. 110, 18934-18939. doi: 10.1073/pnas.1319247110

Bak, D. W., and Weerapana, E. (2015). Cysteine-mediated redox signalling in the mitochondria. Mol. Biosyst. 11, 678-697. doi: 10.1039/C4MB00571F

Baradaran, R., Berrisford, J. M., Minhas, G. S., and Sazanov, L. A. (2013). Crystal structure of the entire respiratory complex I. Nature 494, 443-448. doi: 10.1038 /nature 11871

Barghuti, F., Elian, K., Gomori, J. M., Shaag, A., Edvardson, S., Saada, A., et al. (2008). The unique neuroradiology of complex I deficiency due to NDUFA12L defect. Mol. Genet. Metab. 94, 78-82. doi: 10.1016/j.ymgme.2007.11.013

Beal, M. F. (2002). "Mitochondria in neurodegeneration," in Mitochondrial Disorders: From Pathophysiology to Acquired Defects (Paris: Springer), 17-35.

Belanger, M., Allaman, I., and Magistretti, P. J. (2011). Brain energy metabolism: focus on astrocyte-neuron metabolic cooperation. Cell Metab. 14, 724-738. doi: 10.1016/j.cmet.2011.08.016

Berrisford, J. M., and Sazanov, L. A. (2009). Structural basis for the mechanism of respiratory Complex I. J. Biol. Chem. 284, 29773-29783. doi: 10.1074/jbc.M109.032144

Bobba, A., Amadoro, G., Valenti, D., Corsetti, V., Lassandro, R., and Atlante, A. (2013). Mitochondrial respiratory chain Complexes I and IV are impaired by beta-amyloid via direct interaction and through Complex Idependent ROS production, respectively. Mitochondrion 13, 298-311. doi: 10.1016/j.mito.2013.03.008

Bowling, A. C., Mutisya, E. M., Walker, L. C., Price, D. L., Cork, L. C., and Beal, M. F. (1993). Age-dependent impairment of mitochondrial function in primate brain. J. Neurochem. 60, 1964-1967. doi: 10.1111/j.1471-4159.1993. tb13430.x approaches, where CI assembly factors might play a central role.

\section{AUTHOR CONTRIBUTIONS}

GG and MS conceived the review. GG, RB, SA, SP, and MS wrote the manuscript. GG and MS edited the final version of the review.

\section{ACKNOWLEDGMENTS}

We thank Gordon Leonard for critical reading of the manuscript. The ESRF in-house Research Program supported this work. RB acknowledges funding support from the ESRF Ph. D. Program. SP acknowledges funding support from the Erasmus Program of Università degli Studi di Parma.

\section{SUPPLEMENTARY MATERIAL}

The Supplementary Material for this article can be found online at: http://journal.frontiersin.org/article/10.3389/fmolb. 2016.00043

Braak, H., Braak, E., and Strothjohann, M. (1994). Abnormally phosphorylated tau-protein related to the formation of neurofibrillary tangles and neuropil threads in the cerebral-cortex of sheep and goat. Neurosci. Lett. 171, 1-4. doi: 10.1016/0304-3940(94)90589-4

Buchan, D. W., Minneci, F., Nugent, T. C., Bryson, K., and Jones, D. T. (2013). Scalable web services for the PSIPRED Protein Analysis Workbench. Nucleic Acids Res. 41, W349-W357. doi: 10.1093/nar/gkt381

Butterfield, D. A., Palmieri, E. M., and Castegna, A. (2016). Clinical implications from proteomic studies in neurodegenerative diseases: lessons from mitochondrial proteins. Expert Rev. Proteomics 13, 259-274. doi: 10.1586/14789450.2016.1149470

Calabrese, B., and Halpain, S. (2005). Essential role for the PKC target MARCKS in maintaining dendritic spine morphology. Neuron 48, 77-90. doi: 10.1016/j.neuron.2005.08.027

Calvo, S. E., Tucker, E. J., Compton, A. G., Kirby, D. M., Crawford, G., Burtt, N. P., et al. (2010). High-throughput, pooled sequencing identifies mutations in NUBPL and FOXRED1 in human complex I deficiency. Nat. Genet. 42, 851-858. doi: 10.1038/ng.659

Calvo, S. E., Compton, A. G., Hershman, S. G., Lim, S. C., Lieber, D. S., Tucker, E. J., et al. (2012). Molecular diagnosis of infantile mitochondrial disease with targeted next-generation sequencing. Sci. Transl. Med. 4:118ra10. doi: 10.1126/scitranslmed.3003310

Cao, X., and Fang, Y. (2015). Transducing oxidative stress to death signals in neurons. J. Cell Biol. 211, 741-743. doi: 10.1083/jcb.201510105

Cardoso, S. M., Proenca, M. T., Santos, S., Santana, I., and Oliveira, C. R. (2004). Cytochrome c oxidase is decreased in Alzheimer's disease platelets. Neurobiol. Aging 25, 105-110. doi: 10.1016/S0197-4580(03) 00033-2

Carilla-Latorre, S., Gallardo, M. E., Annesley, S. J., Calvo-Garrido, J., Graña, O., Accari, S. L., et al. (2010). MidA is a putative methyltransferase that is required for mitochondrial complex I function. J. Cell Sci. 123(Pt 10):1674-1683. doi: $10.1242 /$ jcs.066076

Cha, M. Y., Han, S. H., Son, S. M., Hong, H. S., Choi, Y. J., Byun, J., et al. (2012). Mitochondria-specific accumulation of amyloid beta induces mitochondrial dysfunction leading to apoptotic cell death. PLoS ONE 7:e34929. doi: 10.1371/journal.pone.0034929

Chacinska, A., Lind, M., Frazier, A. E., Dudek, J., Meisinger, C., Geissler, A., et al. (2005). Mitochondrial presequence translocase: switching between TOM tethering and motor recruitment involves Tim21 and Tim17. Cell 120, 817-829. doi: 10.1016/j.cell.2005.01.011 
Chatraryamontri, A., Breitkreutz, B. J., Oughtred, R., Boucher, L., Heinicke, S., Chen, D. C., et al. (2015). The BioGRID interaction database: 2015 update. Nucleic Acids Res. 43, D470-D478. doi: 10.1093/nar/gku1204

Chou, J. L., Shenoy, D. V., Thomas, N., Choudhary, P. K., Laferla, F. M., Goodman, S. R., et al. (2011). Early dysregulation of the mitochondrial proteome in a mouse model of Alzheimer's disease. J. Proteomics 74, 466-479. doi: 10.1016/j.jprot.2010.12.012

Clason, T., Ruiz, T., Schagger, H., Peng, G., Zickermann, V., Brandt, U., et al. (2010). The structure of eukaryotic and prokaryotic complex I. J. Struct. Biol. 169, 81-88. doi: 10.1016/j.jsb.2009.08.017

Collet, M., Assouline, Z., Bonnet, D., Rio, M., Iserin, F., Sidi, D., et al. (2016). High incidence and variable clinical outcome of cardiac hypertrophy due to ACAD9 mutations in childhood. Eur. J. Hum. Genet. 24, 1112-1116. doi: 10.1038/ejhg.2015.264

Cox, A. G., Winterbourn, C. C., and Hampton, M. B. (2010). Mitochondrial peroxiredoxin involvement in antioxidant defence and redox signalling. Biochem. J. 425, 313-325. doi: 10.1042/BJ20091541

Darin, N., Oldfors, A., Moslemi, A. R., Holme, E., and Tulinius, M. (2001). The incidence of mitochondrial encephalomyopathies in childhood: clinical features and morphological, biochemical, and DNA anbormalities. Ann. Neurol. 49, 377-383. doi: 10.1002/ana.75

David, D. C., Hauptmann, S., Scherping, I., Schuessel, K., Keil, U., Rizzu, P., et al. (2005). Proteomic and functional analyses reveal a mitochondrial dysfunction in P301L tau transgenic mice. J. Biol. Chem. 280, 23802-23814. doi: 10.1074/jbc.M500356200

Dawson, T. M., and Dawson, V. L. (2003). Molecular pathways of neurodegeneration in Parkinson's disease. Science 302, 819-822. doi: 10.1126/science. 1087753

Deschauer, M., Bamberg, C., Claus, D., Zierz, S., Turnbull, D. M., and Taylor, R. W. (2003). Late-onset encephalopathy associated with a C11777A mutation of mitochondrial DNA. Neurology 60, 1357-1359. doi: 10.1212/01.WNL.0000055869.99975.4B

Devi, L., Raghavendran, V., Prabhu, B. M., Avadhani, N. G., and Anandatheerthavarada, H. K. (2008). Mitochondrial import and accumulation of alpha-synuclein impair complex I in human dopaminergic neuronal cultures and parkinson disease brain. J. Biol. Chem. 283, 9089-9100. doi: 10.1074/jbc.M710012200

Dewulf, J. P., Barrea, C., Vincent, M. F., De Laet, C., Van Coster, R., Seneca, S., et al. (2016). Evidence of a wide spectrum of cardiac involvement due to ACAD9 mutations: report on nine patients. Mol. Genet. Metab. 118, 185-189. doi: 10.1016/j.ymgme.2016.05.005

Dieteren, C. E. J., Willems, P. H. G. M., Vogel, R. O., Swarts, H. G., Fransen, J., Roepman, R., et al. (2008). Subunits of mitochondrial complex i exist as part of matrix- and membrane-associated subcomplexes in living cells. J. Biol. Chem. 283, 34753-34761. doi: 10.1074/jbc.M807323200

Distelmaier, F., Koopman, W. J. H., van den Heuvel, L. P., Rodenburg, R. J., Mayatepek, E., Willems, P. H. G. M., et al. (2009a). Mitochondrial complex I deficiency: from organelle dysfunction to clinical disease. Brain 132, 833-842. doi: 10.1093/brain/awp058

Distelmaier, F., Visch, H. J., Smeitink, J. A. M., Mayatepek, E., Koopman, W. J. H., and Willems, P. H. G. M. (2009b). The antioxidant Trolox restores mitochondrial membrane potential and $\mathrm{Ca} 2+$-stimulated ATP production in human complex I deficiency. J. Mol. Med. 87, 515-522. doi: 10.1007/s00109009-0452-5

Dreyfuss, G., Philipson, L., and Mattaj, I. W. (1988). Ribonucleoprotein-particles in cellular processes. J. Cell Biol. 106, 1419-1425. doi: 10.1083/jcb.106. 5.1419

Dunning, C. J. R., McKenzie, M., Sugiana, C., Lazarou, M., Silke, J., Connelly, A., et al. (2007). Human CIA30 is involved in the early assembly of mitochondrial complex I and mutations in its gene cause disease. EMBO J. 26, 3227-3237. doi: 10.1038/sj.emboj.7601748

Duyckaerts, C., Delatour, B., and Potier, M. C. (2009). Classification and basic pathology of Alzheimer disease. Acta Neuropathol. 118, 5-36. doi: 10.1007/s00401-009-0532-1

Eckert, A., Schulz, K. L., Rhein, V., and Gotz, J. (2010). Convergence of amyloidbeta and tau pathologies on mitochondria in vivo. Mol. Neurobiol. 41, 107-114. doi: 10.1007/s12035-010-8109-5
Efremov, R. G., and Sazanov, L. A. (2010). Crystallisation of the membrane domain of complex I from Escherichia coli. Biochim. Biophys. Acta 1797, 13-13. doi: 10.1016/j.bbabio.2010.04.058

Efremov, R. G., and Sazanov, L. A. (2011). Structure of the membrane domain of respiratory complex I. Nature 476, U414-U462. doi: 10.1038/nature10330

Ellis, C. E., Murphy, E. J., Mitchell, D. C., Golovko, M. Y., Scaglia, F., BarceloCoblijn, G. C., et al. (2005). Mitochondrial lipid abnormality and electron transport chain impairment in mice lacking alpha-synuclein. Mol. Cell. Biol. 25, 10190-10201. doi: 10.1128/MCB.25.22.10190-10201.2005

Elurbe, D. M., and Huynen, M. A. (2016). The origin of the supernumerary subunits and assembly factors of complex I: a treasure trove of pathway evolution. Biochim. Biophys. Acta 1857, 971-979. doi: 10.1016/j.bbabio.2016.03.027

Fassone, E., Taanman, J. W., Hargreaves, I. P., Sebire, N. J., Cleary, M. A., Burch, M., et al. (2011). Mutations in the mitochondrial complex I assembly factor NDUFAF1 cause fatal infantile hypertrophic cardiomyopathy. J. Med. Genet. 48, 691-697. doi: 10.1136/jmedgenet-2011-100340

Fassone, E., and Rahman, S. (2012). Complex I deficiency: clinical features, biochemistry and molecular genetics. J. Med. Genet. 49, 578-590. doi: 10.1136/jmedgenet-2012-101159

Federico, A., Cardaioli, E., Da Pozzo, P., Formichi, P., Gallus, G. N., and Radi, E. (2012). Mitochondria, oxidative stress and neurodegeneration. J. Neurol. Sci. 322, 254-262. doi: 10.1016/j.jns.2012.05.030

Fernandez-Vizarra, E., Tiranti, V., and Zeviani, M. (2009). Assembly of the oxidative phosphorylation system in humans: what we have learned by studying its defects. Biochim. Biophys. Acta 1793, 200-211. doi: 10.1016/j.bbamcr.2008.05.028

Formosa, L. E., Mimaki, M., Frazier, A. E., McKenzie, M., Stait, T. L., Thorburn, D. R., et al. (2015). Characterization of mitochondrial FOXRED1 in the assembly of respiratory chain complex I. Hum. Mol. Genet. 24, 2952-2965. doi: 10.1093/hmg/ddv058

Friedland-Leuner, K., Stockburger, C., Denzer, I., Eckert, G. P., and Müller, W. E. (2014). Mitochondrial dysfunction: cause and consequence of Alzheimer's disease. Prog. Mol. Biol. Transl. Sci. 127, 183-210. doi: 10.1016/B978-0-12394625-6.00007-6

Gatt, A. P., Duncan, O. F., Attems, J., Francis, P. T., Ballard, C. G., and Bateman, J. M. (2016). Dementia in parkinson's disease is associated with enhanced mitochondrial complex I deficiency. Mov. Disord. 31, 352-359. doi: $10.1002 / \mathrm{mds} .26513$

Gerards, M., Sluiter, W., van den Bosch, B. J., de Wit, L. E., Calis, C. M., Frentzen, M., et al. (2010). Defective complex I assembly due to C20orf7 mutations as a new cause of leigh syndrome. J. Med. Genet. 47, 507-512. doi: 10.1136/jmg.2009.067553

Gerards, M., van den Bosch, B. J. C., Danhauser, K., Serre, V., van Weeghel, M., Wanders, R. J. A., et al. (2011). Riboflavin-responsive oxidative phosphorylation complex I deficiency caused by defective ACAD9: new function for an old gene. Brain 134, 210-219. doi: 10.1093/brain/awq273

Ghaloul-Gonzalez, L., Goldstein, A., Walsh Vockley, C., Dobrowolski, S. F., Biery, A., Irani, A., et al. (2016). Mitochondrial respiratory chain disorders in the Old Order Amish population. Mol. Genet. Metab. 118, 296-303. doi: 10.1016/j.ymgme.2016.06.005

Ghezzi, D., and Zeviani, M. (2012). Assembly factors of human mitochondrial respiratory chain complexes: physiology and pathophysiology. Adv. Exp. Med. Biol. 748, 65-106. doi: 10.1007/978-1-4614-3573-0_4

Gu, M., Cooper, J. M., Taanman, J. W., and Schapira, A. H. V. (1998). Mitochondrial DNA transmission of the mitochondrial defect in Parkinson's disease. Ann. Neurol. 44, 177-186. doi: 10.1002/ana.410440207

Guarani, V., Paulo, J., Zhai, B., Huttlin, E. L., Gygi, S. P., and Harper, J. W. (2014). TIMMDC1/C3orf1 functions as a membrane-embedded mitochondrial complex i assembly factor through association with the MCIA complex. Mol. Cell. Biol. 34, 847-861. doi: 10.1128/MCB.01551-13

Haack, T. B., Danhauser, K., Haberberger, B., Hoser, J., Strecker, V., Boehm, D., et al. (2010). Exome sequencing identifies ACAD9 mutations as a cause of complex I deficiency. Nat. Genetics 42, 1131-1134. doi: 10.1038/ng.706

Haelterman, N. A., Yoon, W. H., Sandoval, H., Jaiswal, M., Shulman, J. M., and Bellen, H. J. (2014). A mitocentric view of parkinson's disease. Annu. Rev. Neurosci. 37, 137-159. doi: 10.1146/annurev-neuro-071013-014317 
Hall, T. (2011). BioEdit: An important software for molecular biology. GERF Bull. Biosci. 2, 60-61.

Hall, C. N., Klein-Flugge, M. C., Howarth, C., and Attwell, D. (2012). Oxidative phosphorylation, not glycolysis, powers presynaptic and postsynaptic mechanisms underlying brain information processing. J. Neurosci. 32, 8940-8951. doi: 10.1523/JNEUROSCI.0026-12.2012

Heide, H., Bleier, L., Steger, M., Ackermann, J., Drose, S., Schwamb, B., et al. (2012). Complexome profiling identifies TMEM126B as a component of the mitochondrial complex I assembly complex. Cell Metab. 16, 538-549. doi: 10.1016/j.cmet.2012.08.009

Henchcliffe, C., and Beal, M. F. (2008). Mitochondrial biology and oxidative stress in parkinson disease pathogenesis. Nat. Clin. Pract. Neurol. 4, 600-609. doi: 10.1038/ncpneuro0924

Hertz, L., Peng, L., and Dienel, G. A. (2007). Energy metabolism in astrocytes: high rate of oxidative metabolism and spatiotemporal dependence on glycolysis/glycogenolysis. J. Cereb. Blood Flow Metab. 27, 219-249. doi: 10.1038/sj.jcbfm. 9600343

Herzer, M., Koch, J., Prokisch, H., Rodenburg, R., Rauscher, C., Radauer, W., et al. (2010). Leigh disease with brainstem involvement in complex I deficiency due to assembly factor NDUFAF2 defect. Neuropediatrics 41, 30-34. doi: $10.1055 / \mathrm{s}-0030-1255062$

Hirst, J., and Roessler, M. M. (2015). Energy conversion, redox catalysis and generation of reactive oxygen species by respiratory complex I. Biochim. Biophys. Acta 1857, 872-883. doi: 10.1016/j.bbabio.2015.12.009

Hoefs, S. J., Dieteren, C. E., Rodenburg, R. J., Naess, K., Bruhn, H., Wibom, R., et al. (2009). Baculovirus complementation restores a novel NDUFAF2 mutation causing complex I deficiency. Hum. Mutat. 30, E728-E736. doi: 10.1002/humu.21037

Hroudova, J., Singh, N., and Fisar, Z. (2014). Mitochondrial dysfunctions in neurodegenerative diseases: relevance to Alzheimer's disease. Biomed. Res. Int. 2014:175062. doi: 10.1155/2014/175062

Hyman, B. T., Phelps, C. H., Beach, T. G., Bigio, E. H., Cairns, N. J., Carrillo, M. C., et al. (2012). National institute on aging-alzheimer's association guidelines for the neuropathologic assessment of alzheimer's disease. Alzheimers Dement. 8, 1-13. doi: 10.1016/j.jalz.2011.10.007

Imanishi, H., Yokota, M., Mori, M., Shimizu, A., Nakada, K., and Hayashi, J. (2011). Nuclear but not mitochondrial DNA involvement in respiratory complex I defects found in senescence-accelerated mouse strain, SAMP8. Exp. Anim. 60, 397-404. doi: 10.1538/expanim.60.397

Janssen, R., Smeitink, J., Smeets, R., and van den Heuvel, L. (2002). CIA30 complex I assembly factor: a candidate for human complex I deficiency? Hum. Genet. 110, 264-270. doi: 10.1007/s00439-001-0673-3

Janssen, R. J. R. J., Nijtmans, L. G., van den Heuvel, L. P., and Smeitink, J. A. M. (2006). Mitochondrial complex I: structure, function and pathology. J. Inherit. Metab. Dis. 29, 499-515. doi: 10.1007/s10545-006-0362-4

Janssen, R. J., Distelmaier, F., Smeets, R., Wijnhoven, T., Østergaard, E., Jaspers, N. G., et al. (2009). Contiguous gene deletion of ELOVL7, ERCC8 and NDUFAF2 in a patient with a fatal multisystem disorder. Hum. Mol. Genet. 18, 3365-3374. doi: $10.1093 / \mathrm{hmg} / \mathrm{ddp} 276$

Jeong, S. Y., and Seol, D. W. (2008). The role of mitochondria in apoptosis. BMB Rep. 41, 11-22. doi: 10.5483/BMBRep.2008.41.1.011

Keeney, P. M., Xie, J., Capaldi, R. A., and Bennett, J. P. (2006). Parkinson's disease brain mitochondrial complex I has oxidatively damaged subunits and is functionally impaired and misassembled. J. Neurosci. 26, 5256-5264. doi: 10.1523/JNEUROSCI.0984-06.2006

Kelley, L. A., Mezulis, S., Yates, C. M., Wass, M. N., and Sternberg, M. J. (2015). The Phyre2 web portal for protein modeling, prediction and analysis. Nat. Protoc. 10, 845-858. doi: 10.1038/nprot.2015.053

Kevelam, S. H., Rodenburg, R. J., Wolf, N. I., Ferreira, P., Lunsing, R. J., Nijtmans, L. G., et al. (2013). NUBPL mutations in patients with complex I deficiency and a distinct MRI pattern. Neurology 80, 1577-1583. doi: 10.1212/WNL.0b013e31828f1914

Kim, S. H., Vlkolinsky, R., Cairns, N., Fountoulakis, M., and Lubec, G. (2001). The reduction of $\mathrm{NADH}$ ubiquinone oxidoreductase 24 -and $75-\mathrm{kDa}$ subunits in brains of patients with Down syndrome and Alzheimer's disease. Life Sci. 68, 2741-2750. doi: 10.1016/S0024-3205(01)01074-8

Kim, S. H., Vlkolinsky, R., Cairns, N., and Lubec, G. (2000). Decreased levels of complex III core protein 1 and complex $\mathrm{V}$ beta chain in brains from patients with Alzheimer's disease and down syndrome. Cell. Mol. Life Sci. 57, 1810-1816. doi: 10.1007/PL00000661

Kirby, D. M., Crawford, M., Cleary, M. A., Dahl, H. H., Dennett, X., and Thorburn, D. R. (1999). Respiratory chain complex I deficiency: an underdiagnosed energy generation disorder. Neurology 52, 1255-1264. doi: 10.1212/WNL.52. 6.1255

Komen, J. C., Distelmaier, F., Koopman, W. J. H., Wanders, R. J. A., Smeitink, J., and Willems, P. H. M. G. (2007). Phytanic acid impairs mitochondrial respiration through protonophoric action Cell Mol. Life Sci. 64, 3271-3281. doi: 10.1007/s00018-007-7357-7

Koopman, W. J., Beyrath, J., Fung, C. W., Koene, S., Rodenburg, R. J., Willems, P. H., et al. (2016). Mitochondrial disorders in children: toward development of small-molecule treatment strategies. EMBO Mol. Med. 8, 311-327. doi: 10.15252/emmm.201506131

Koopman, W. J., Verkaart, S., Visch, H. J., van Emst-de Vries, S., Nijtmans, L. G., Smeitink, J. A., et al. (2007). Human NADH:ubiquinone oxidoreductase deficiency: radical changes in mitochondrial morphology? Am. J. Physiol. Cell Physiol. 293, C22-C29. doi: 10.1152/ajpcell.00194.2006

Koopman, W. J. H., Distelmaier, F., Smeitink, J. A. M., and Willems, P. H. G. M. (2013). OXPHOS mutations and neurodegeneration. EMBO J. 32, 9-29. doi: 10.1038/emboj.2012.300

Kopp, E., Medzhitov, R., Carothers, J., Xiao, C. C., Douglas, I., Janeway, C. A., et al. (1999). ECSIT is an evolutionarily conserved intermediate in the Toll/IL-1 signal transduction pathway. Gen. Dev. 13, 2059-2071. doi: 10.1101/gad.13.16.2059

Kuffner, R., Rohr, A., Schmiede, A., Krull, C., and Schulte, U. (1998). Involvement of two novel chaperones in the assembly of mitochondrial NADH: ubiquinone oxidoreductase (complex I). J. Mol. Biol. 283, 409-417. doi: 10.1006/jmbi.1998.2114

Kurz, M., Martin, H., Rassow, J., Pfanner, N., and Ryan, M. T. (1999). Biogenesis of tim proteins of the mitochondrial carrier import pathway: differential targeting mechanisms and crossing over with the main import pathway. Mol. Biol. Cell 10, 2461-2474. doi: 10.1091/mbc.10.7.2461

Kussmaul, L., and Hirst, J. (2006). The mechanism of superoxide production by NADH:ubiquinone oxidoreductase (complex I) from bovine heart mitochondria. Proc. Natl. Acad. Sci. U.S.A. 103, 7607-7612. doi: 10.1073/pnas.0510977103

LaFerla, F. M., Green, K. N., and Oddo, S. (2007). Intracellular amyloid-beta in Alzheimer's disease. Nat. Rev. Neurosci. 8, 499-509. doi: 10.1038/nrn2168

Larkin, M. A., Blackshields, G., Brown, N. P., Chenna, R., McGettigan, P. A., McWilliam, H., et al. (2007). Clustal W and Clustal X version 2.0. Bioinformatics 23, 2947-8. doi: 10.1093/bioinformatics/btm404

Lasserre, J. P., Dautant, A., Aiyar, R. S., Kucharczyk, R., Glatigny, A., TribouillardTanvier, D., et al. (2015). Yeast as a system for modeling mitochondrial disease mechanisms and discovering therapies. Dis. Model. Mech. 8, 509-526. doi: $10.1242 / \mathrm{dmm} .020438$

Lazarou, M., McKenzie, M., Ohtake, A., Thorburn, D. R., and Ryan, M. T. (2007). Analysis of the assembly profiles for mitochondrial- and nuclearDNA-encoded subunits into complex I. Mol. Cell. Biol. 27, 4228-4237. doi: 10.1128/MCB.00074-07

Leigh, D. (1951). Subacute necrotizing encephalomyelopathy in an infant. J. Neurol. Neurosurg. Psychiatr. 14, 216-221. doi: 10.1136/jnnp.14.3.216

Leman, G., Gueguen, N., Desquiret-Dumas, V., Kane, M. S., Wettervald, C., Chupin, S., et al. (2015). Assembly defects induce oxidative stress in inherited mitochondrial complex I deficiency. Int. J. Biochem. Cell Biol. 65, 91-103. doi: 10.1016/j.biocel.2015.05.017

Leslie, N., Wang, X., Peng, Y., Valencia, C. A., Khuchua, Z., Hata, J., et al. (2016). Neonatal multiorgan failure due to ACAD9 mutation and complex I deficiency with mitochondrial hyperplasia in liver, cardiac myocytes, skeletal muscle, and renal tubules. Hum. Pathol. 49, 27-32. doi: 10.1016/j.humpath.2015. 09.039

Letts, J. A., and Sazanov, L. A. (2015). Gaining mass: the structure of respiratory complex I - from bacterial towards mitochondria! versions. Curr. Opin. Struct. Biol. 33, 135-145. doi: 10.1016/j.sbi.2015.08.008

Leuner, K., Schutt, T., Kurz, C., Eckert, S. H., Schiller, C., Occhipinti, A., et al. (2012). Mitochondrion-derived reactive oxygen species lead to enhanced amyloid beta formation. Antioxid. Redox Signal. 16, 1421-1433. doi: $10.1089 /$ ars.2011.4173 
Li, X. Y., Fang, P., Mai, J. T., Choi, E. T., Wang, H., and Yang, X. F. (2013). Targeting mitochondrial reactive oxygen species as novel therapy for inflammatory diseases and cancers. J. Hematol. Oncol. 6:19. doi: 10.1186/1756-8722-6-19

Liang, L. P., Huang, J., Fulton, R., Day, B. J., and Patel, M. (2007). An orally active catalytic metalloporphyrin protects against 1-methyl-4-phenyl-1,2,3,6tetrahydropyridine neurotoxicity in vivo. J. Neurosci. 27, 4326-4333. doi: 10.1523/JNEUROSCI.0019-07.2007

Lightowlers, R. N., and Chrzanowska-Lightowlers, Z. M. A. (2008). PPR (pentatricopeptide repeat) proteins in mammals: important aids to mitochondrial gene expression. Biochem. J. 416, e5-e6. doi: 10.1042/BJ20081942

Lightowlers, R. N., and Chrzanowska-Lightowlers, Z. M. A. (2013). Human pentatricopeptide proteins. only a few and what do they do? RNA Biol. 10, 1433-1438. doi: 10.4161/rna.24770

Lin, M. T., and Beal, M. F. (2006). Mitochondrial dysfunction and oxidative stress in neurodegenerative diseases. Nature 443, 787-795. doi: 10.1038/nature05292

Mailloux, R. J. (2015). Teaching the fundamentals of electron transfer reactions in mitochondria and the production and detection of reactive oxygen species. Redox Biol. 4, 381-398. doi: 10.1016/j.redox.2015.02.001

Manczak, M., Anekonda, T. S., Henson, E., Park, B. S., Quinn, J., and Reddy, P. H. (2006). Mitochondria are a direct site of A beta accumulation in Alzheimer's disease neurons: implications for free radical generation and oxidative damage in disease progression. Hum. Mol. Genet. 15, 1437-1449. doi: 10.1093/hmg/ddl066

Marchler-Bauer, A., Derbyshire, M. K., Gonzales, N. R., Lu, S., Chitsaz, F., Geer, L. Y., et al. (2015). CDD: NCBI's conserved domain database. Nucleic Acids Res. 43, D222-D226. doi: 10.1093/nar/gku1221

Martin, L. J., Pan, Y., Price, A. C., Sterling, W., Copeland, N. G., Jenkins, N. A., et al. (2006). Parkinson's disease alpha-synuclein transgenic mice develop neuronal mitochondrial degeneration and cell death. J. Neurosci. 26, 41-50. doi: 10.1523/JNEUROSCI.4308-05.2006

McAndrew, R. P., Wang, Y., Mohsen, A. W., He, M., Vockley, J., and Kim, J. J. (2008). Structural basis for substrate fatty acyl chain specificity: crystal structure of human very-long-chain acyl-CoA dehydrogenase. J. Biol. Chem. 283, 9435-9443. doi: 10.1074/jbc.M709135200

Mckenzie, M., and Ryan, M. T. (2010). Assembly Factors of Human mitochondrial complex I and their defects in disease. IUBMB Life 62, 497-502. doi: 10.1002/iub.335

McKenzie, M., Tucker, E. J., Compton, A. G., Lazarou, M., George, C., Thorburn, D. R., et al. (2011). Mutations in the gene encoding C8orf38 block complex I assembly by inhibiting production of the mitochondria-encoded subunit ND1. J. Mol. Biol. 414, 413-426. doi: 10.1016/j.jmb.2011.10.012

Mick, D. U., Dennerlein, S., Wiese, H., Reinhold, R., Pacheu-Grau, D., Lorenzi, I., et al. (2012). MITRAC links mitochondrial protein translocation to respiratory-Chain assembly and translational regulation. Cell 151, 1528-1541. doi: 10.1016/j.cell.2012.11.053

Mimaki, M., Wang, X. N., McKenzie, M., Thorburn, D. R., and Ryan, M. T. (2012). Understanding mitochondrial complex I assembly in health and disease. Biochim. Biophys. Acta 1817, 851-862. doi: 10.1016/j.bbabio.2011.08.010

Mitchell, A., Chang, H. Y., Daugherty, L., Fraser, M., Hunter, S., Lopez, R., et al. (2015). The interpro protein families database: the classification resource after 15 years. Nucleic Acids Res. 43, D213-D221. doi: 10.1093/nar/ gku1243

Miwa, S., Jow, H., Baty, K., Johnson, A., Czapiewski, R., Saretzki, G., et al. (2014). Low abundance of the matrix arm of complex I in mitochondria predicts longevity in mice. Nat. Commun. 5:3837. doi: 10.1038/ncomms4837

Moreira, P. I., Carvalho, C., Zhu, X. W., Smith, M. A., and Perry, G. (2010a). Mitochondrial dysfunction is a trigger of Alzheimer's disease pathophysiology. Biochim. Biophys. Acta 1802, 2-10. doi: 10.1016/j.bbadis.2009.10.006

Moreira, P. I., Zhu, X., Wang, X., Lee, H. G., Nunomura, A., Petersen, R. B., et al. (2010b). Mitochondria: a therapeutic target in neurodegeneration. Biochim. Biophys. Acta 1802, 212-220. doi: 10.1016/j.bbadis.2009.10.007

Moreno-Lastres, D., Fontanesi, F., Garcia-Consuegra, I., Martin, M. A., Arenas, J., Barrientos, A., et al. (2012). Mitochondrial complex I plays an essential role in human respirasome assembly. Cell Metab. 15, 324-335. doi: 10.1016/j.cmet.2012.01.015

Morley, J. E., Armbrecht, H. J., Farr, S. A., and Kumar, V. B. (2012). The senescence accelerated mouse (SAMP8) as a model for oxidative stress and Alzheimer's disease. Biochim. Biophys. Acta 1822, 650-656. doi: 10.1016/j.bbadis.2011.11.015

Morley, J. E., Kumar, V. B., Bernardo, A. E., Farr, S. A., Uezu, K., Tumosa, N., et al. (2000). Beta-amyloid precursor polypeptide in SAMP8 mice affects learning and memory. Peptides 21, 1761-1767. doi: 10.1016/S0196-9781(00) 00342-9

Murphy, M. P. (2009). How mitochondria produce reactive oxygen species. Biochem. J. 417, 1-13. doi: 10.1042/BJ20081386

Mutisya, E. M., Bowling, A. C., and Beal, M. F. (1994). Cortical cytochromeoxidase activity is reduced in Alzheimers-disease. J. Neurochem. 63, 2179-2184. doi: 10.1046/j.1471-4159.1994.63062179.x

Nouws, J., Nijtmans, L., Houten, S. M., van den Brand, M., Huynen, M., Venselaar, H., et al. (2010). Acyl-CoA dehydrogenase 9 is required for the biogenesis of oxidative phosphorylation complex I. Cell Metab. 12, 283-294. doi: 10.1016/j.cmet.2010.08.002

Nouws, J., Nijtmans, L. G. J., Smeitink, J. A., and Vogel, R. O. (2012). Assembly factors as a new class of disease genes for mitochondrial complex I deficiency: cause, pathology and treatment options. Brain 135, 12-22. doi: 10.1093/brain/awr261

Nouws, J., te Brinke, H., Nijtmans, L. G., and Houten, S. M. (2014). ACAD9, a complex I assembly factor with a moonlighting function in fatty acid oxidation deficiencies. Hum. Mol. Genet. 23, 1311-1319. doi: 10.1093/hmg/ddt521

Ogilvie, I., Kennaway, N. G., and Shoubridge, E. A. (2005). A molecular chaperone for mitochondrial complex I assembly is mutated in a progressive encephalopathy. J. Clin. Invest. 115, 2784-2792. doi: 10.1172/JCI26020

Olahova, M., Hardy, S. A., Hall, J., Yarham, J. W., Haack, T. B., Wilson, W. C., et al. (2015). LRPPRC mutations cause early-onset multisystem mitochondrial disease outside of the French-Canadian population. Brain 138, 3503-3519. doi: 10.1093/brain/awv291

Orchard, S. (2014). Data standardization and sharing the work of the HUPO-PSI. Biochim. Biophys. Acta 1844, 82-87. doi: 10.1016/j.bbapap.2013.03.011

Pagliarini, D. J., Calvo, S. E., Chang, B., Sheth, S. A., Vafai, S. B., Ong, S. E., et al. (2008). A mitochondrial protein compendium elucidates complex I disease biology. Cell 134, 112-123. doi: 10.1016/j.cell.2008.06.016

Parker, W. D., and Parks, J. K. (2005). Mitochondrial ND5 mutations in idiopathic Parkinson's disease. Biochem. Biophys. Res. Commun. 326, 667-669. doi: 10.1016/j.bbrc.2004.11.093

Potluri, P., Yadava, N., and Scheffler, I. E. (2004). The role of the ESSS protein in the assembly of a functional and stable mammalian mitochondrial complex I (NADH-ubiquinone oxidoreductase). Eur. J. Biochem. 271, 3265-3273. doi: 10.1111/j.1432-1033.2004.04260.x

Pronicka, E., Piekutowska-Abramczuk, D., Ciara, E., Trubicka, J., Rokicki, D., Karkucińska-Więckowska, A., et al. (2016). New perspective in diagnostics of mitochondrial disorders: two years' experience with whole-exome sequencing at a national paediatric centre. J. Transl. Med. 14, 174. doi: 10.1186/s12967-0160930-9

Rackham, O., and Filipovska, A. (2012). The role of mammalian PPR domain proteins in the regulation of mitochondrial gene expression. Biochim. Biophys. Acta 1819, 1008-1016. doi: 10.1016/j.bbagrm.2011.10.007

Rahman, S., Blok, R. B., Dahl, H. H., Danks, D. M., Kirby, D. M., Chow, C. W., et al. (1996). Leigh syndrome: clinical features and biochemical and DNA abnormalities. Ann. Neurol. 39, 343-351. doi: 10.1002/ana.410390311

Rebecchi, M. J., and Scarlata, S. (1998). Pleckstrin homology domains: a common fold with diverse functions. Annu. Rev. Biophys. Biomol. Struct. 27, 503-528. doi: 10.1146/annurev.biophys.27.1.503

Reddy, P. H., Manczak, M., Mao, P., Calkins, M. J., Reddy, A. P., and Shirendeb, U. (2010). Amyloid-beta and mitochondria in aging and Alzheimer's disease: implications for synaptic damage and cognitive decline. J. Alzheimers Dis. 20, S499-S512. doi: 10.3233/JAD-2010-100504

Rhein, V., Song, X., Wiesner, A., Ittner, L. M., Baysang, G., Meier, F., et al. (2009). Amyloid-beta and tau synergistically impair the oxidative phosphorylation system in triple transgenic Alzheimer's disease mice. Proc. Natl. Acad. Sci. U.S.A. 106, 20057-20062. doi: 10.1073/pnas.0905529106

Rodenburg, R. J. (2016). Mitochondrial complex I-linked disease. Biochim. Biophys. Acta 1857, 938-945. doi: 10.1016/j.bbabio.2016.02.012

Saada, A., Edvardson, S., Rapoport, M., Shaag, A., Amry, K., Miller, C., et al. (2008). C6ORF66 is an assembly factor of mitochondrial complex I. Am. J. Hum. Genet. 82, 32-38. doi: 10.1016/j.ajhg.2007.08.003 
Saada, A., Vogel, R. O., Hoefs, S. J., van den Brand, M. A., Wessels, H. J., Willems, P. H., et al. (2009). Mutations in NDUFAF3 (C3ORF60), encoding an NDUFAF4 (C6ORF66)-interacting complex I assembly protein, cause fatal neonatal mitochondrial disease. Am. J. Hum. Genet. 84, 718-727. doi: 10.1016/j.ajhg.2009.04.020

Sanchez-Caballero, L., Guerrero-Castillo, S., and Nijtmans, L. (2016). Unraveling the complexity of mitochondrial complex I assembly: a dynamic process. Biochim. Biophys. Acta 1857, 980-990. doi: 10.1016/j.bbabio.2016.03.031

Sazanov, L. A. (2014). The mechanism of coupling between electron transfer and proton translocation in respiratory complex I. J. Bioenerg. Biomembr. 46, 247-253. doi: 10.1007/s10863-014-9554-z

Sazanov, L. A. (2015). A giant molecular proton pump: structure and mechanism of respiratory complex I. Nat. Rev. Mol. Cell Biol. 16, 375-388. doi: $10.1038 / \mathrm{nrm} 3997$

Schagger, H., de Coo, R., Bauer, M. F., Hofmann, S., Godinot, C., and Brandt, U. (2004). Significance of respirasomes for the assembly/stability of human respiratory chain complex I. J. Biol. Chem. 279, 36349-36353. doi: 10.1074/jbc.M404033200

Schapira, A. H. (2012). Mitochondrial diseases. Lancet 379, 1825-1834. doi: 10.1016/S0140-6736(11)61305-6

Schapira, A. H. V., Mann, V. M., Cooper, J. M., Dexter, D., Daniel, S. E., Jenner, P., et al. (1990). Anatomic and disease specificity of nadh coql reductase (Complex-I) deficiency in Parkinsons-disease. J. Neurochem. 55, 2142-2145. doi: 10.1111/j.1471-4159.1990.tb05809.x

Scheffler, I. E. (2010). Assembling Complex I with ACAD9. Cell Metab. 12, 211-212. doi: 10.1016/j.cmet.2010.08.008

Sedlacek, V., Klumpler, T., Marek, J., and Kucera, I. (2014). The Structural and Functional Basis of Catalysis Mediated by NAD(P)H:acceptor Oxidoreductase (FerB) of Paracoccus denitrificans. PLOS ONE 9:e96262. doi: 10.1371/journal.pone.0096262

Selkoe, D. J. (2001). Presenilins, beta-amyloid precursor protein and the molecular basis of Alzheimer's disease. Clin. Neurosci. Res. 1, 91-103. doi: 10.1016/S15662772(00)00016-5

Sheftel, A. D., Stehling, O., Pierik, A. J., Netz, D. J., Kerscher, S., Elsässer, H. P., et al. (2009). Human ind1, an iron-sulfur cluster assembly factor for respiratory complex I. Mol. Cell. Biol. 29, 6059-6073. doi: 10.1128/MCB. 00817-09

Sherer, T. B., Richardson, J. R., Testa, C. M., Seo, B. B., Panov, A. V., Yagi, T., et al. (2007). Mechanism of toxicity of pesticides acting at complex I: relevance to environmental etiologies of Parkinson's disease. J. Neurochem. 100, 1469-1479. doi: 10.1111/j.1471-4159.2006.04333.x

Scholte, H. R., Busch, H. F., Bakker, H. D., Bogaard, J. M., Luyt-Houwen, I. E., and Kuyt, L. P. (1995). Riboflavin-responsive complex I deficiency. Biochim. Biophys. Acta 1271, 75-83. doi: 10.1016/0925-4439(95)00013-T

Simon, D. K., Lin, M. T., Zheng, L. Y., Liu, G. J., Ahn, C. H., Kim, L. M., et al. (2004). Somatic mitochondrial DNA mutations in cortex and substantia nigra in aging and Parkinson's disease. Neurobiol. Aging 25, 71-81. doi: 10.1016/S0197-4580(03)00037-X

Soler-Lopez, M., Badiola, N., Zanzoni, A., and Aloy, P. (2012). Towards Alzheimer's root cause: ECSIT as an integrating hub between oxidative stress, inflammation and mitochondrial dysfunction. Bioessays 34, 532-541. doi: 10.1002/bies.201100193

Soler-Lopez, M., Zanzoni, A., Lluis, R., Stelzl, U., and Aloy, P. (2011). Interactome mapping suggests new mechanistic details underlying Alzheimer's disease. Genome Res. 21, 364-376. doi: 10.1101/gr.114280.110

Song, D. D., Shults, C. W., Sisk, A., Rockenstein, E., and Masliah, E. (2004). Enhanced substantia nigra mitochondrial pathology in human alpha-synuclein transgenic mice after treatment with MPTP. Exp. Neurol. 186, 158-172. doi: 10.1016/S0014-4886(03)00342-X

St-Pierre, J., Buckingham, J. A., Roebuck, S. J., and Brand, M. D. (2002). Topology of superoxide production from different sites in the mitochondrial electron transport chain. J. Biol. Chem. 277, 44784-44790. doi: 10.1074/jbc. M207217200

Sugiana, C., Pagliarini, D. J., McKenzie, M., Kirby, D. M., Salemi, R., Abu-Amero, K. K., et al. (2008). Mutation of C20orf7 disrupts complex I assembly and causes lethal neonatal mitochondrial disease. Am. J. Hum. Genet. 83, 468-478. doi: 10.1016/j.ajhg.2008.09.009
Sultana, R., Mecocci, P., Mangialasche, F., Cecchetti, R., Baglioni, M., and Butterfield, D. A. (2011). Increased protein and lipid oxidative damage in mitochondria isolated from lymphocytes from patients with Alzheimer's disease: insights into the role of oxidative stress in Alzheimer's disease and initial investigations into a potential biomarker for this dementing disorder. J. Alzheimers Dis. 24, 77-84. doi: 10.3233/JAD-2011-101425

Swerdlow, R. H., Burns, J. M., and Khan, S. M. (2010). The Alzheimer's Disease mitochondrial cascade hypothesis. J. Alzheimers Dis. 20, S265-S279. doi: 10.3233/JAD-2010-100339

Swerdlow, R. H., Parks, J. K., Miller, S. W., Tuttle, J. B., Trimmer, P. A., Sheehan, J. P., et al. (1996). Origin and functional consequences of the complex I defect in Parkinson's disease. Ann. Neurol. 40, 663-671. doi: 10.1002/ana.410400417

Swigonova, Z., Mohsen, A. W., and Vockley, J. (2009). Acyl-CoA dehydrogenases: dynamic history of protein family evolution. J. Mol. Evol. 69, 176-193. doi: 10.1007/s00239-009-9263-0

Tamagno, E., Guglielmotto, M., Monteleone, D., and Tabaton, M. (2012). Amyloidbeta production: major link between oxidative stress and BACE1. Neurotox. Res. 22, 208-219. doi: 10.1007/s12640-011-9283-6

Taylor, R. W., Pyle, A., Griffin, H., Blakely, E. L., Duff, J., He, L. P., et al. (2014). Use of whole-exome sequencing to determine the genetic basis of multiple mitochondrial respiratory chain complex deficiencies. JAMA 312, 68-77. doi: 10.1001/jama.2014.7184

Telford, J. E., Kilbride, S. M., and Davey, G. P. (2009). Complex I is rate-limiting for oxygen consumption in the nerve terminal. J. Biol. Chem. 284, 9109-9114. doi: 10.1074/jbc.M809101200

Tillement, L., Lecanu, L., and Papadopoulos, V. (2011). Alzheimer's disease: effects of beta-amyloid on mitochondria. Mitochondrion 11, 13-21. doi: 10.1016/j.mito.2010.08.009

Torraco, A., Peralta, S., Iommarini, L., and Diaz, F. (2015). Mitochondrial diseases part I: mouse models of OXPHOS deficiencies caused by defects in respiratory complex subunits or assembly factors. Mitochondrion 21, 76-91. doi: 10.1016/j.mito.2015.01.009

Tucker, E. J., Mimaki, M., Compton, A. G., McKenzie, M., Ryan, M. T., and Thorburn, D. R. (2012). Next-generation sequencing in molecular diagnosis: NUBPL mutations highlight the challenges of variant detection and interpretation. Hum. Mutat. 33, 411-418. doi: 10.1002/humu.21654

Valla, J., Berndt, J. D., and Gonzalez-Lima, F. (2001). Energy hypometabolism in posterior cingulate cortex of Alzheimer's patients: superficial laminar cytochrome oxidase associated with disease duration. J. Neurosci. 21, 4923-4930.

Vartak, R. S., Semwal, M. K., and Bai, Y. D. (2014). An update on complex I assembly: the assembly of players. J. Bioenerg. Biomem. 46, 323-328. doi: 10.1007/s10863-014-9564-x

Verkaart, S., Koopman, W. J., Cheek, J., van Emst-de Vries, S. E., van den Heuvel, L. W., Smeitink, J. A., et al. (2007a). Mitochondrial and cytosolic thiol redox state are not detectably altered in isolated human NADH:ubiquinone oxidoreductase deficiency. Biochim. Biophys. Acta 1772, 1041-1051. doi: 10.1016/j.bbadis.2007.05.004

Verkaart, S., Koopman, W. J., van Emst-de Vries, S. E., Nijtmans, L. G., van den Heuvel, L. W., Smeitink, J. A., et al. (2007b). Superoxide production is inversely related to complex I activity in inherited complex I deficiency. Biochim. Biophys. Acta 1772, 373-381. doi: 10.1016/j.bbadis.2006.12.009

Viegas, A., Bras, N. F., Cerqueira, N. M. F. S. A., Fernandes, P. A., Prates, J. A. M., Fontes, C. M. G. A., et al. (2008). Molecular determinants of ligand specificity in family 11 carbohydrate binding modules - an NMR, X-ray crystallography and computational chemistry approach. FEBS J. 275, 2524-2535. doi: 10.1111/j.1742-4658.2008.06401.x

Vinothkumar, K. R., Zhu, J. P., and Hirst, J. (2014). Architecture of mammalian respiratory complex I. Nature 515, 80-84. doi: 10.1038/nature13686

Vogel, R. O., Janssen, R. J. R. J., Ugalde, C., Grovenstein, M., Huijbens, R. J., Visch, H. J., et al. (2005). Human mitochondrial complex I assembly is mediated by NDUFAF1. FEBS J. 272, 5317-5326. doi: 10.1111/j.1742-4658.2005.04928.x

Vogel, R. O., Janssen, R. J. R. J., van den Brand, M. A. M., Dieteren, C. E. J., Verkaart, S., Koopman, W. J. H., et al. (2007a). Cytosolic signaling protein Ecsit also localizes to mitochondria where it interacts with chaperone NDUFAF1 and functions in complex I assembly. Gen. Dev. 21, 615-624. doi: $10.1101 / \operatorname{gad} .408407$ 
Vogel, R. O., Smeltink, J. A. M., and Nijtmans, L. G. J. (2007b). Human mitochondrial complex I assembly: a dynamic and versatile process. Biochim. Biophys. Acta 1767, 1215-1227. doi: 10.1016/j.bbabio.2007.07.008

Wakatsuki, S., Furuno, A., Ohshima, M., and Araki, T. (2015). Oxidative stress-dependent phosphorylation activates ZNRF1 to induce neuronal/axonal degeneration. J. Cell Biol. 211, 881-896. doi: 10.1083/jcb.201506102

Wang, W., Karamanlidis, G., and Tian, R. (2016). Novel targets for mitochondrial medicine. Sci. Transl. Med. 8:326rv3. doi: 10.1126/scitranslmed.aac7410

Weissig, V., Cheng, S. M., and D'Souza, G. G. M. (2004). Mitochondrial pharmaceutics. Mitochondrion 3, 229-244. doi: 10.1016/j.mito.2003.11.002

Welander, H., Franberg, J., Graff, C., Sundstrom, E., Winblad, B., and Tjernberg, L. O. (2009). A beta 43 is more frequent than A beta 40 in amyloid plaque cores from Alzheimer disease brains. J. Neurochem. 110, 697-706. doi: 10.1111/j.1471-4159.2009.06170.x

West, A. P., Brodsky, I. E., Rahner, C., Woo, D. K., Erdjument-Bromage, H., Tempst, P., et al. (2011). TLR signalling augments macrophage bactericidal activity through mitochondrial ROS. Nature 472, U476-U543. doi: 10.1038/nature09973

Wi, S. M., Moon, G., Kim, J., Kim, S. T., Shim, J. H., Chun, E., et al. (2014). TAK1ECSIT-TRAF6 complex plays a key role in the TLR4 signal to activate NF- $\kappa B$. J. Biol. Chem. 289, 35205-35214. doi: 10.1074/jbc.M114.597187

Willem, M., Tahirovic, S., Busche, M. A., Ovsepian, S. V., Chafai, M., Kootar, S., et al. (2015). eta-Secretase processing of APP inhibits neuronal activity in the hippocampus. Nature 526, 443-447. doi: 10.1038/nature14864

Willems, P. H., Valsecchi, F., Distelmaier, F., Verkaart, S., Visch, H. J., Smeitink, J. A., et al. (2008). Mitochondrial Ca2+ homeostasis in human NADH:ubiquinone oxidoreductase deficiency. Cell Calcium 44, 123-133. doi: 10.1016/j.ceca.2008.01.002

Winklhofer, K. F., and Haass, C. (2010). Mitochondrial dysfunction in Parkinson's disease. Biochim. Biophys. Acta 1802, 29-44. doi: 10.1016/j.bbadis.2009.08.013

Wirth, C., Brandt, U., Hunte, C., and Zickermann, V. (2016). Structure and function of mitochondrial complex I. Biochim. Biophys. Acta 1857, 902-914. doi: 10.1016/j.bbabio.2016.02.013

Wong, A., Cavelier, L., Collins-Schramm, H. E., Seldin, M. F., McGrogan, M., Savontaus, M. L., et al. (2002). Differentiation-specific effects of LHON mutations introduced into neuronal NT2 cells. Hum. Mol. Genet. 11, 431-438. doi: $10.1093 / \mathrm{hmg} / 11.4 .431$
Wu, L., Peng, J., Ma, Y., He, F., Deng, X., Wang, G., et al. (2016). Leukodystrophy associated with mitochondrial complex I deficiency due to a novel mutation in the NDUFAF1 gene. Mitochondrial DNA A DNA Mapp. Seq. Anal. 27, 1034-1037. doi: 10.3109/19401736.2014. 926543

Xiao, C. C., Shim, J. H., Kluppel, M., Zhang, S. S. M., Dong, C., Flavell, R. A., et al. (2003). Ecsit is required for Bmp signaling and mesoderm formation during mouse embryogenesis. Gen. Dev. 17, 2933-2949. doi: 10.1101/gad. 1145603

Yeh, A. P., Chatelet, C., Soltis, S. M., Kuhn, P., Meyer, J., and Rees, D. C. (2000). Structure of a thioredoxin-like [2Fe-2S] ferredoxin from Aquifex aeolicus. J. Mol. Biol. 300, 587-595. doi: 10.1006/jmbi.20 00.3871

Zhang, L., Zhang, S., Maezawa, I., Trushin, S., Minhas, P., Pinto, M., et al. (2015). Modulation of mitochondrial complex I activity averts cognitive decline in multiple animal models of familial Alzheimer's disease. EBioMedicine 2, 294-305. doi: 10.1016/j.ebiom.2015.03.009

Zickermann, V., Wirth, C., Nasiri, H., Siegmund, K., Schwalbe, H., Hunte, C., et al. (2015). Mechanistic insight from the crystal structure of mitochondrial complex I. Science 347, 44-49. doi: 10.1126/science. 1259859

Zurita Rendón, O., Silva Neiva, L., Sasarman, F., and Shoubridge, E. A. (2014) The arginine methyltransferase NDUFAF7 is essential for complex I assembly and early vertebrate embryogenesis. Hum. Mol. Genet. 23, 5159-5170. doi: $10.1093 / \mathrm{hmg} / \mathrm{ddu} 239$

Conflict of Interest Statement: The authors declare that the research was conducted in the absence of any commercial or financial relationships that could be construed as a potential conflict of interest.

Copyright (C) 2016 Giachin, Bouverot, Acajaoui, Pantalone and Soler-López. This is an open-access article distributed under the terms of the Creative Commons Attribution License (CC BY). The use, distribution or reproduction in other forums is permitted, provided the original author(s) or licensor are credited and that the original publication in this journal is cited, in accordance with accepted academic practice. No use, distribution or reproduction is permitted which does not comply with these terms. 